\title{
Methane and carbon dioxide fluxes over a lake: comparison between eddy covariance, floating chambers and boundary layer method
}

\author{
Kukka-Maaria Erkkilä ${ }^{1}$, Anne Ojala ${ }^{1,2,3}$, David Bastviken ${ }^{4}$, Tobias Biermann ${ }^{5}$, Jouni J. Heiskanen ${ }^{1}$, \\ Anders Lindroth ${ }^{6}$, Olli Peltola ${ }^{1}$, Miitta Rantakari ${ }^{1,7}$, Timo Vesala ${ }^{1,2}$, and Ivan Mammarella ${ }^{1}$ \\ ${ }^{1}$ Institute for Atmospheric and Earth System Research/Physics, Faculty of Science, University of Helsinki, P.O. Box 68, \\ 00014 Helsinki, Finland \\ ${ }^{2}$ Institute for Atmospheric and Earth System Research/Forest Sciences, Faculty of Agriculture and Forestry, University of \\ Helsinki, P.O. Box 27, 00014 Helsinki, Finland \\ ${ }^{3}$ Faculty of Biological and Environmental Sciences, University of Helsinki, Niemenkatu 73, 15140 Lahti, Finland \\ ${ }^{4}$ Department of Thematic Studies - Environmental Change, Linköping University, Linköping, Sweden \\ ${ }^{5}$ Centre for Environmental and Climate Research, Lund University, Sölvegatan 37, 22362 Lund, Sweden \\ ${ }^{6}$ Department of Physical Geography and Ecosystem Sciences, Lund University, Sölvegatan 12, 22362 Lund, Sweden \\ ${ }^{7}$ Faculty of Biological and Environmental Sciences, University of Helsinki, P.O. Box 65, 00014 Helsinki, Finland
}

Correspondence: Kukka-Maaria Erkkilä (kukka-maaria.erkkila@helsinki.fi)

Received: 20 February 2017 - Discussion started: 2 March 2017

Revised: 21 November 2017 - Accepted: 4 December 2017 - Published: 19 January 2018

\begin{abstract}
Freshwaters bring a notable contribution to the global carbon budget by emitting both carbon dioxide $\left(\mathrm{CO}_{2}\right)$ and methane $\left(\mathrm{CH}_{4}\right)$ to the atmosphere. Global estimates of freshwater emissions traditionally use a wind-speed-based gas transfer velocity, $k_{\mathrm{CC}}$ (introduced by Cole and Caraco, 1998), for calculating diffusive flux with the boundary layer method (BLM). We compared $\mathrm{CH}_{4}$ and $\mathrm{CO}_{2}$ fluxes from $\mathrm{BLM}$ with $k_{\mathrm{CC}}$ and two other gas transfer velocities $\left(k_{\mathrm{TE}}\right.$ and $k_{\mathrm{HE}}$ ), which include the effects of water-side cooling to the gas transfer besides shear-induced turbulence, with simultaneous eddy covariance (EC) and floating chamber (FC) fluxes during a 16-day measurement campaign in September 2014 at Lake Kuivajärvi in Finland. The measurements included both lake stratification and water column mixing periods. Results show that BLM fluxes were mainly lower than $\mathrm{EC}$, with the more recent model $k_{\mathrm{TE}}$ giving the best fit with EC fluxes, whereas FC measurements resulted in higher fluxes than simultaneous EC measurements. We highly recommend using up-to-date gas transfer models, instead of $k_{\mathrm{CC}}$, for better flux estimates.

BLM $\mathrm{CO}_{2}$ flux measurements had clear differences between daytime and night-time fluxes with all gas transfer models during both stratified and mixing periods, whereas EC measurements did not show a diurnal behaviour in $\mathrm{CO}_{2}$
\end{abstract}

flux. $\mathrm{CH}_{4}$ flux had higher values in daytime than night-time during lake mixing period according to EC measurements, with highest fluxes detected just before sunset. In addition, we found clear differences in daytime and night-time concentration difference between the air and surface water for both $\mathrm{CH}_{4}$ and $\mathrm{CO}_{2}$. This might lead to biased flux estimates, if only daytime values are used in BLM upscaling and flux measurements in general.

FC measurements did not detect spatial variation in either $\mathrm{CH}_{4}$ or $\mathrm{CO}_{2}$ flux over Lake Kuivajärvi. EC measurements, on the other hand, did not show any spatial variation in $\mathrm{CH}_{4}$ fluxes but did show a clear difference between $\mathrm{CO}_{2}$ fluxes from shallower and deeper areas. We highlight that while all flux measurement methods have their pros and cons, it is important to carefully think about the chosen method and measurement interval, as well as their effects on the resulting flux.

\section{Introduction}

Freshwaters (rivers, streams, reservoirs and lakes) are found to be a net source of carbon to the atmosphere (Cole et al., 1994) due to supersaturation of especially carbon dioxide 
$\left(\mathrm{CO}_{2}\right)$ but also methane $\left(\mathrm{CH}_{4}\right)$. Global estimates of the contribution of lakes to the carbon cycle are highly variable and uncertain (Cole et al., 2007; Tranvik et al., 2009; Bastviken et al., 2011; Raymond et al., 2013), but they are significant compared to the terrestrial sources and sinks.

Global estimates are usually based on the boundary layer method (BLM, also known as boundary layer model) that uses wind speed (via gas transfer velocity $k$ ) and concentration gradient between the air and surface water as the only factors driving the gas exchange (Cole and Caraco, 1998). According to recent studies, this upscaling approach strongly underestimates current emissions from lakes and improved methods are needed (e.g. Schubert et al., 2012; Mammarella et al., 2015). Heiskanen et al. (2014) and Tedford et al. (2014) suggest $k$ models based also on heat flux and water turbulence measurements for more accurate estimates.

A widely used direct flux measurement technique is the floating chamber (FC) method, where the vertical flux at the air-water interface is calculated from the concentration increase within the chamber during the measurement period (Livingston and Hutchinson, 1995). This method has a small source area and is representative of the measurement point only. On the other hand, it can be used to quantify the spatial variability of the gas emissions (Natchimuthu et al., 2016). FC method is laborious, but inexpensive, and does not need extensive data post-processing. However, similar to BLM, it requires automatic data loggers or access to a gas analyser, such as a gas chromatograph, in the case of manual sampling. FC measurements also disturb the air-water interface and might affect the gas exchange by creating artificial turbulence, especially with anchored chambers in running waters (Lorke et al., 2015). However, these effects are minor for drifting chambers following the water (Lorke et al., 2015). FC measurements on standing water can also correspond well with non-invasive methods for certain chamber types and deployment methods (Gålfalk et al., 2013).

Recently, also direct eddy covariance (EC) flux measurements have grown their popularity in lake studies, but there are still only a few sites with long data sets (e.g. Mammarella et al., 2015; Huotari et al., 2011). Instead of measuring just a specific point of the lake, the EC method provides flux estimates over a much larger source area, also known as footprint (Aubinet et al., 2012), and as opposed to chamber measurements, it does not disturb the air-water interface. EC measurements are, however, quite expensive and require extensive data post-processing.

In this study, we compared these three flux measurement methods, including three different gas transfer velocities for BLM approach, over a boreal lake in southern Finland for both $\mathrm{CH}_{4}$ and $\mathrm{CO}_{2}$ during an intensive field campaign from 11 to 26 September 2014. We also studied spatial variation of $\mathrm{CH}_{4}$ and $\mathrm{CO}_{2}$ fluxes over the $\mathrm{EC}$ footprint area with manual floating chambers, while simultaneously estimating fluxes with the EC method and BLM. Our aim is to compare the three methods and make recommendations for future mea- surements based on our results. Because current upscaling estimates are based on these methods, comparison is needed to reduce the uncertainties in current estimates of the role of freshwaters in global carbon cycle. Such a comparison also gives valuable information on measurement technique development needs, and so far there is only one comparative study including all three methods for $\mathrm{CH}_{4}$ in a temperate lake (Schubert et al., 2012). This is, to our knowledge, the first study including the three measurement methods for both $\mathrm{CH}_{4}$ and $\mathrm{CO}_{2}$ in a boreal lake, even though the boreal zone harbours a large fraction of the global lakes (Lehner and Döll, 2004; Verpoorter et al., 2014).

\section{Materials and methods}

\subsection{Site description and measurements}

The study site was the humic, oblong Lake Kuivajärvi situated in southern Finland $\left(61^{\circ} 50^{\prime} \mathrm{N}, 24^{\circ} 17^{\prime} \mathrm{E}\right)$, in the middle of a managed mixed coniferous forest, close to the SMEAR II station (Station for Measuring Ecosystem Atmosphere Relations; Hari and Kulmala, 2005). The lake has a maximum depth of $13.2 \mathrm{~m}$, mean depth of $6.3 \mathrm{~m}$, length of $2.6 \mathrm{~km}$ and surface area of $0.62 \mathrm{~km}^{2}$ (Fig. 1a). Due to the oblong shape, the wind usually blows along the longest fetch (Mammarella et al., 2015). Lake Kuivajärvi has two separate basins and a measurement raft is mounted on the south basin, near the deepest part of the lake. Lake Kuivajärvi has median light extinction coefficient $K_{\mathrm{d}}=0.59 \mathrm{~m}^{-1}$ as estimated in Heiskanen et al. (2015). The low water clarity is mainly due to high dissolved organic carbon (DOC) concentration in the lake. Lake Kuivajärvi is a dimictic lake that mixes thoroughly right after ice-out usually in the beginning of May, stratifies for summertime and then mixes again at the latest in October, until it freezes and stratifies again underneath the ice cover for 5-6 months (Heiskanen et al., 2015). These spring and autumn mixing periods usually bring high amounts of $\mathrm{CH}_{4}$ and $\mathrm{CO}_{2}$ from the hypolimnion and bottom sediments of the lake to the atmosphere (Miettinen et al., 2015).

Continuous measurements of carbon exchange between water and air started in 2010 and the lake belongs to the ICOS (Integrated Carbon Observation System) network. Flux measurement apparatus with the EC system on the raft consists of an ultrasonic anemometer (USA-1, Metek GmbH, Elmshorn, Germany), a closed-path infrared gas analyser (LI-7200, LICOR Inc., Nebraska, USA) for measuring $\mathrm{CO}_{2}$ and water vapour $\left(\mathrm{H}_{2} \mathrm{O}\right)$ mixing ratios and a closed-path gas analyser (Picarro G1301-f, Picarro Inc., California, USA) for measuring $\mathrm{CH}_{4}$ and $\mathrm{H}_{2} \mathrm{O}$ mixing ratios. $\mathrm{EC}$ measurement height was $1.8 \mathrm{~m}$ above the lake surface. Measurement frequency was $10 \mathrm{~Hz}$ and a $30 \mathrm{~min}$ averaging period was used in this study. $\mathrm{CO}_{2}$ measurements with LI-7200 were stopped on 25 September. Air temperature and relative humidity were measured using a Rotronic MP102H/HC2-S3 (Rotronic Instru- 


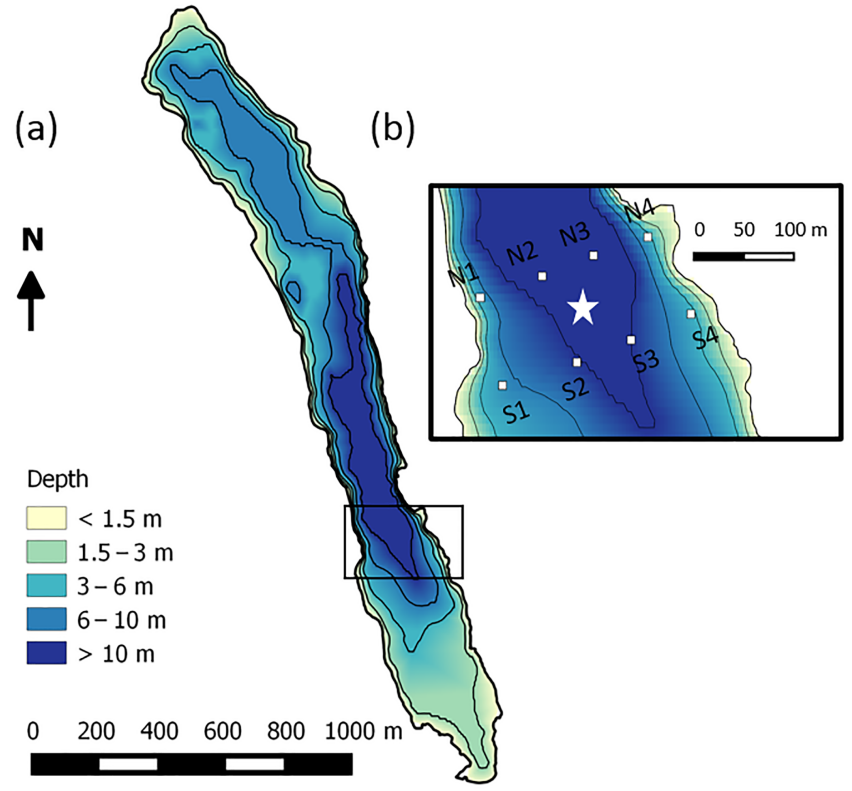

Figure 1. (a) Bathymetry of Lake Kuivajärvi and (b) floating chamber measurement spots (white squares) around the EC measurement raft (white star).

ment Corp., NY), while radiation components were measured with a CNR1 net radiometer (Kipp \& Zonen, Delft, Netherlands). These data were collected every $5 \mathrm{~s}$ and averaged over $30 \mathrm{~min}$.

Water temperature at depths $0.2,0.5,1.0,1.5,2.0,2.5$, 3.0, 3.5, 5.0, 6.0, 7.0, 8.0, 10.0 and $12.0 \mathrm{~m}$ was measured with a chain of Pt100 temperature sensors. Water column $\mathrm{CO}_{2}$ concentration was measured at depths $0.2,1.5,2.5$ and $7.0 \mathrm{~m}$ using semipermeable silicone tubing in the water and circulating air in a closed loop continuously to the analyser (CARBOCAP ${ }^{\circledR}$ GMP343, Vaisala Oyj, Vantaa, Finland). The measurement system is explained in detail in Hari et al. (2008), Heiskanen et al. (2014) and Mammarella et al. (2015). Water column temperature and $\mathrm{CO}_{2}$ data were collected at the raft every $5 \mathrm{~s}$ and averaged over 30 min periods.

Another gas analyser (Ultraportable Greenhouse Gas Analyzer, Los Gatos Inc., USA) was used for measuring $\mathrm{CH}_{4}$ and $\mathrm{CO}_{2}$ concentrations in the air at $1 \mathrm{~m}$ height and in the water at depths 0.2 and $11 \mathrm{~m}$. The analyser was connected stepwise to three different intakes - one in air and two in water - and a dryer, consisting of a container filled with silica gel. For all levels, air was circulated in closed loop between the gas analyser and the different intakes. The internal pump of the gas analyser was used for this circulation of air at a rate of $1.2 \mathrm{~L} \mathrm{~min}^{-1}$. The air intake consisted of a ca. $10 \mathrm{~cm}$ long diffusive membrane (Accurel S6/2, PP, AKZO NOBEL) that was placed under a protective rain cover. The water intakes at each level consisted of a $4.1 \mathrm{~m}$ long, $8 \mathrm{~mm}$ diameter silicon tube that was bundled and attached to a metal disc ca. $25 \mathrm{~cm}$ in diameter, to give a well-defined measurement depth. The dryer was added to the system to remove excess moisture that could have entered into the tubing system by condensation. The air intake was located $1 \mathrm{~m}$ above the lake surface and the water intakes were located at 0.2 and $11 \mathrm{~m}$ depths. A full measurement cycle was completed over $2 \mathrm{~h}$. The air intake was connected to the gas analyser for $10 \mathrm{~min}$, while the water intakes were connected for $45 \mathrm{~min}$ each, but data were averaged only during the last $5 \mathrm{~min}$ of each connection period in order to allow equilibration to the new concentration after a change of intake. After each measurement cycle for the water intakes, the air was circulated through the dryer. The gas analyser was checked against a standard after the measurement campaign and found to be accurate within the specifications of the standard.

Manual floating chamber measurements of $\mathrm{CH}_{4}$ and $\mathrm{CO}_{2}$ fluxes were done with two replicate chambers at eight different spots (Fig. 1b) in the EC footprint area 2-3 times a day (morning, afternoon and night/early morning) during the period 11-22 September. Unfortunately, multiple daily measurements were only possible in the first 11 days of the campaign and only a few measurements were done during 22 26 September due to high wind and hard weather conditions towards the end. Measurement lines were perpendicular to the shoreline. The line north of the raft was chosen when the wind was blowing from north, and south line was chosen during southerly winds. Measurement spots N2/S2 and $\mathrm{N} 3 / \mathrm{S} 3$ were about $10 \mathrm{~m}$ deep, and points N1/S1 and N4/S4 were about $3 \mathrm{~m}$ deep. They were chosen so that the distance to the measurement raft was about $50 \mathrm{~m}$ and the points were marked with buoys.

Chambers used in this study were polyethylene/plexiglas plastic buckets equipped with styrofoam floats and sampling outlets (Gålfalk et al., 2013). Chambers reached approximately $3 \mathrm{~cm}$ into the water and their height above water was about $9.6 \mathrm{~cm}$. The closing time for the chambers was $20 \mathrm{~min}$ and sampling interval $5 \mathrm{~min}$. Air samples were taken with syringes and injected into $12 \mathrm{~mL}$ Labco Exetainer ${ }^{\circledR}$ vials (Labco Ltd., Lampeter, Ceredigion, UK) and analysed with gas chromatograph (GC). The GC system consisted of a Gilson GX-271 liquid handler (Gilson Inc., Middleton, USA), a $1 \mathrm{~mL}$ Valco 10-port valve (VICI Valco Instrument Co. Inc., Houston, USA) and an Agilent 7890A GC system (Agilent Technologies, Santa Clara, USA) equipped with a flame-ionization detector (temperature $210^{\circ} \mathrm{C}$ ).

In addition to automatic water concentration measurements, we took manual water samples for comparison. Two replicate water samples were taken into $60 \mathrm{~mL}$ plastic syringes. After sampling, $30 \mathrm{~mL}$ of water was pushed out and replaced by $30 \mathrm{~mL}$ of $\mathrm{N}_{2}$ gas. The syringes were placed in a water bath at $20^{\circ} \mathrm{C}$ temperature for $30 \mathrm{~min}$. Then the samples were equilibrated by shaking the syringes vigorously for $3 \mathrm{~min}$. The samples of the syringe headspace gas were injected into $12 \mathrm{~mL}$ Labco Exetainer ${ }^{\circledR}$ vials (Labco Ltd., Lampeter, Ceredigion, UK) and analysed with the same GC as manual air samples. Final gas 
concentrations in the water were calculated using Henry's law. Henry's law solubility constants at $298.15 \mathrm{~K}$ were $1.4 \times 10^{-3} \mathrm{~mol} \mathrm{dm}^{-3}$ bar $^{-1}$ for $\mathrm{CH}_{4}$ (Warneck and Williams, 2012) and $3.4 \times 10^{-2} \mathrm{~mol} \mathrm{dm}^{-3} \mathrm{bar}^{-1}$ for $\mathrm{CO}_{2}$ (Seinfeld and Pandis, 2016).

\subsection{Data processing and quality criteria}

\subsubsection{Eddy covariance data}

EC data were processed using EddyUH software (Mammarella et al., 2016) according to the approaches in Mammarella et al. (2015). Briefly, spikes in the data were removed on the basis of a maximum difference being allowed between two adjacent points, and 2-D coordinate rotation was done so that the wind component $u$ is directed parallel to the mean horizontal wind. Linear detrending was used for calculating the turbulent fluctuations. Lag time was determined from the maximum of the cross-covariance function and cross-wind correction was applied to sonic temperature data (Liu et al., 2001). High-frequency spectral corrections were calculated according to Mammarella et al. (2009).

Data quality was ensured with tests for flux stationarity $(\mathrm{FST} \leq 1$ was approved) and limits for kurtosis $(1<\mathrm{Ku}<8)$ and skewness $(-2<\mathrm{Sk}<2$ ) (Vickers and Mahrt, 1997). Wind directions other than along the lake were ignored to ensure that only fluxes from the lake were included. Accepted wind directions were $130^{\circ}<\mathrm{WD}<180^{\circ}$ and $320^{\circ}<$ $\mathrm{WD}<350^{\circ}$. For gas fluxes, a criterion for standard deviation of the mixing ratios was also used. During night-time, the standard deviation often increased, indicating that there was advection of $\mathrm{CH}_{4}$ and $\mathrm{CO}_{2}$ from the forest uphill to the lake causing scatter in the flux measurements. This scatter was found to be small when the standard deviation of $\mathrm{CO}_{2}$ was less than $3 \mathrm{ppm}$ and thus $\mathrm{CO}_{2}$ mixing ratio (and flux) data with standard deviation larger than $3 \mathrm{ppm}$ were removed. The same procedure was also done for $\mathrm{CH}_{4}$, with the threshold value for standard deviation being $0.003 \mathrm{ppm}$. After all data quality criteria, the data coverage was 27 and $32 \%$ of the original data for $\mathrm{CO}_{2}$ and $\mathrm{CH}_{4}$ fluxes, and 83 and $80 \%$ for latent and sensible heat fluxes, respectively. The EC flux detection limit was determined as $3 \sigma$, where $\sigma$ is the total random uncertainty estimated according to Finkelstein and Sims (2001). This estimate for the detection limit takes into account both instrumental noise and one-point sampling random error (Rannik et al., 2016). On average, detection limit of $30 \mathrm{~min}$ averaged $\mathrm{CH}_{4}$ flux was $0.81 \mathrm{nmol} \mathrm{m}^{-2} \mathrm{~s}^{-1}$ and $\mathrm{CO}_{2}$ flux $0.84 \mu \mathrm{mol} \mathrm{m} \mathrm{m}^{-2} \mathrm{~s}^{-1}$. Average detection limits scaled for the daily median fluxes were $0.12 \mathrm{nmol} \mathrm{m}^{-2} \mathrm{~s}^{-1}$ and $0.12 \mu \mathrm{mol} \mathrm{m}^{-2} \mathrm{~s}^{-1}$ for $\mathrm{CH}_{4}$ and $\mathrm{CO}_{2}$, respectively. The average source area of the EC system reaches $100-300 \mathrm{~m}$ from the measurement raft, depending on the stability conditions (Mammarella et al., 2015).

Heat fluxes measured with the EC system were gap-filled using a bulk model depending on water-air temperature dif- ference multiplied by wind speed and vapour pressure difference multiplied by wind speed for sensible and latent heat fluxes, respectively. The coefficients for these relationships were found from a linear fit between measured EC fluxes and the parameters, similar to Mammarella et al. (2015).

\subsubsection{Chamber flux calculations}

The gas concentration increase inside the chambers was linear over a short closure time $(20 \mathrm{~min})$ combined with low flux levels. Flux calculation was conducted according to Duc et al. (2013):

$F=\frac{\mathrm{d} \chi}{\mathrm{d} t} \frac{p_{\mathrm{a}} V}{R T A}$,

where $\frac{\mathrm{d} \chi}{\mathrm{d} t}$ is the slope of the linear fit to concentration increase inside the chamber during the closure time $\left(\mu \mathrm{LL}^{-1} \mathrm{~s}^{-1}\right), p_{\mathrm{a}}$ ambient pressure $(\mathrm{Pa}), V$ chamber volume $\left(\mathrm{m}^{3}\right), A$ the area of the surface that the chamber covers $\left(\mathrm{m}^{2}\right)$, $R$ universal gas constant $\left(\mathrm{J} \mathrm{mol}^{-1} \mathrm{~K}^{-1}\right)$, and $T$ ambient temperature $(\mathrm{K})$. Measurements were accepted when there were no leakages during the chamber closure. If measurements from both replicate chambers (located within $1 \mathrm{~m}$ distance from each other) were successful, then an average flux from these two chambers was used.

\subsection{Boundary layer method}

Diffusive gas exchange $F$ between the air and water was determined according to the boundary layer model

$F=k\left(c_{\mathrm{aq}}-c_{\mathrm{eq}}\right)$,

where $k$ is the gas transfer velocity $\left(\mathrm{m} \mathrm{s}^{-1}\right), c_{\mathrm{aq}}$ the gas concentration $\left(\mathrm{mol} \mathrm{m}^{-3}\right)$ in surface water and $c_{\mathrm{eq}}$ the concentration $\left(\mathrm{mol} \mathrm{m}^{-3}\right)$ that the surface water would have if it was in equilibrium with the above air (MacIntyre et al., 1995). Equilibrium gas concentrations were calculated from measurements of mixing ratio $\chi_{\mathrm{c}}$ and air pressure $p_{\mathrm{a}}$ and corrected with Henry's constant $k_{\mathrm{H}}$ according to the solubility of the gas in the water:

$c_{\mathrm{eq}}=\chi_{\mathrm{c}} p_{\mathrm{a}} k_{\mathrm{H}}$.

For this study, gas transfer velocity was calculated according to Cole and Caraco (1998), Tedford et al. (2014) and Heiskanen et al. (2014). Gas concentrations for flux calculations were measured automatically at the measurement raft. Wind speed, sensible and latent heat fluxes, and air friction velocity were measured with the EC system.

\subsubsection{Gas transfer velocity}

The most simple and the most often used model for gas transfer velocity $k$ is the one proposed by Cole and Caraco (1998):

$k_{\mathrm{CC}}=\left(2.07+0.215 U_{10}^{1.7}\right)\left(\frac{S c}{600}\right)^{-0.5}$, 
where $U_{10}$ represents the wind speed at $10 \mathrm{~m}$ height (in $\mathrm{m} \mathrm{s}^{-1}$, approximated by $U_{10}=1.22 U$, where $U$ is the measured wind speed at $1.5 \mathrm{~m}$ height) and $S c$ is the Schmidt number calculated for local conditions. This model considers wind as the only factor causing water turbulence and driving the gas exchange.

A model by Tedford et al. (2014), on the other hand, suggests the importance of the buoyancy flux $\beta$ driven turbulence during cooling periods, so that the turbulent dissipation rate $\varepsilon_{\mathrm{TE}}$ becomes

$\varepsilon_{\mathrm{TE}}=\left\{\begin{array}{ll}\frac{c_{1} u_{* \mathrm{w}}^{3}}{\kappa z}+c_{2}|\beta| & \text { if } \beta<0, \\ \frac{c_{3} u_{* \mathrm{w}}^{3}}{\kappa z} & \text { if } \beta \geq 0\end{array}\right.$,

where $c_{1}=0.56, c_{2}=0.77$ and $c_{3}=0.6$ are dimensionless constants, $u_{* \mathrm{w}}$ is the friction velocity in the water, $\kappa=0.41$ is the von Kármán constant and depth $z$ is here used as constant $0.15 \mathrm{~m}$ (Tedford et al., 2014; Mammarella et al., 2015). Friction velocity in the water $u_{* \mathrm{w}}$ was calculated from direct EC measurements of air friction velocity $u_{* \mathrm{a}}$, so that

$u_{* \mathrm{w}}=u_{* \mathrm{a}} \sqrt{\frac{\rho_{\mathrm{a}}}{\rho_{\mathrm{w}}}}$,

where $\rho_{\mathrm{a}}$ is the air density and $\rho_{\mathrm{w}}$ water density. Buoyancy flux $\beta$ was calculated according to Imberger (1985):

$\beta=\frac{g \alpha_{\mathrm{t}} H_{\mathrm{eff}}}{\rho_{\mathrm{w}} C_{\mathrm{p}}}$,

where $g$ is the gravitational acceleration, $\alpha_{\mathrm{t}}$ coefficient of thermal expansion of water, $H_{\text {eff }}$ the effective heat flux (i.e. latent and sensible heat fluxes and portion of shortwave radiation that is not trapped to the mixing layer are subtracted from the net radiation), and $C_{\mathrm{p}}$ the specific heat of water. Buoyancy flux is positive when the effective heat flux is positive and the lake is heating, whereas negative buoyancy and effective heat fluxes indicate cooling of the lake. Gas transfer velocity $k$ can then be calculated according to the surface renewal model

$k_{\mathrm{TE}}=c_{4}\left(\varepsilon_{\mathrm{TE}} v\right)^{1 / 4} S c^{-1 / 2}$,

where $c_{4}=0.5$ is a dimensionless constant and $v$ kinematic viscosity of water $\left(\mathrm{m}^{2} \mathrm{~s}^{-1}\right)$.

Another $k$ model that takes heat flux into account as a factor creating turbulence was developed by Heiskanen et al. (2014):

$k_{\mathrm{HE}}=\sqrt{\left(C_{1} U\right)^{2}+\left(C_{2} w_{*}\right)^{2}} S c^{-\frac{1}{2}}$,

Here $C_{1}=0.00015$ and $C_{2}=0.07$ are dimensionless constants defined for Lake Kuivajärvi (Heiskanen et al., 2014), $w_{*}$ is the convective velocity, defined as

$w_{*}=\sqrt[3]{-\beta z_{\mathrm{AML}}}$, and $z_{\mathrm{AML}}$ is the depth of the actively mixing layer $(\mathrm{m})$, where temperature varies within $0.25^{\circ} \mathrm{C}$ of the surface water temperature. This model was developed in Lake Kuivajärvi for $\mathrm{CO}_{2}$ fluxes but had not been tested for $\mathrm{CH}_{4}$ before this study.

All three $k$ models are hereafter referred to as they are presented in the formulas.

\section{Results and discussion}

The results of the measurement campaign are divided into two sub-periods (11 days of stratified period 11-21 September and 5 days of lake mixing period 22-26 September 2014) according to lake stratification and environmental conditions during the campaign, since gas transfer processes differ between these two periods. The water column started its autumn turnover on 22 September, but the mixing did not yet reach the lake bottom. Measurements of $\mathrm{CH}_{4}$ and $\mathrm{CO}_{2}$ fluxes with BLM, EC and the more sporadic FC method are first compared by examining daily median as well as daytime and night-time fluxes. Spatial variation is then studied by checking median $\mathrm{FC}$ fluxes in different measurement points against simultaneous EC fluxes.

\subsection{Environmental conditions and water column temperature}

Weather at the beginning of the measurement campaign in September 2014 was warm with a maximum air temperature of $18^{\circ} \mathrm{C}$ (Fig. 2). Sensible and latent heat fluxes were low, less than $100 \mathrm{~W} \mathrm{~m}^{-2}$ and winds were weak, around $2 \mathrm{~m} \mathrm{~s}^{-1}$, and mostly from south. Air temperature exceeded surface water temperature during the afternoons causing negative sensible heat fluxes. Night-time air temperatures were more than $10^{\circ} \mathrm{C}$ colder than during daytime. The lake was clearly stratified with bottom temperature around $9^{\circ} \mathrm{C}$, and surface water temperature about $16^{\circ} \mathrm{C}$ (Fig. 3a). On 14 September, the mixing layer of the lake deepened from $5 \mathrm{~m}$ to around 6-7 $\mathrm{m}$ due to night-time cooling. Warm daytime air temperature then caused the surface water to stratify again. Similar occasions of night-time cooling were experienced on 16 and 17 September. The sun rose at 05:45 and set at 18:45 during the stratified period.

On 22 September, a cold front turned winds north bringing cold air and rain ( $11 \mathrm{~mm}$ on 22 September). Air temperature dropped to even $0^{\circ} \mathrm{C}$ on 24 September and wind speeds as high as $8 \mathrm{~m} \mathrm{~s}^{-1}$ were measured at the lake. A drop in the air temperature caused a large temperature difference between air and lake surface water that together with high wind speed caused high, even $200 \mathrm{~W} \mathrm{~m}^{-2}$, positive (upward) sensible and latent heat fluxes on 22 and 23 September and a large negative $\left(-400 \mathrm{~W} \mathrm{~m}^{-2}\right)$ effective heat flux, resulting in a negative buoyancy flux during this cooling period. Cooling also caused the starting of the autumn mixing of Lake Kuivajärvi and the thermocline reached a depth of $8 \mathrm{~m}$ on 


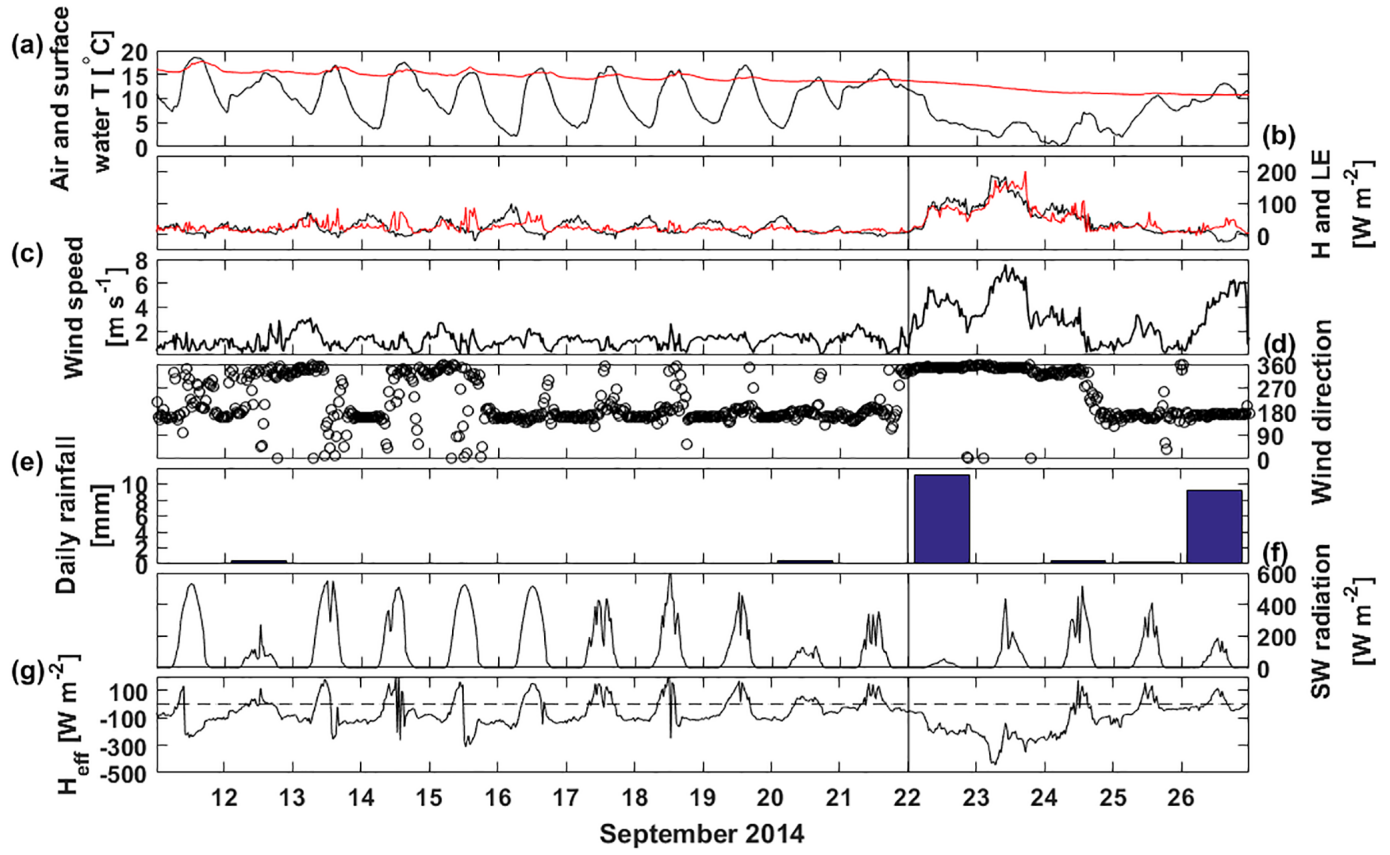

Figure 2. Half-hour averages of (a) measured air temperature (black) and lake surface water temperature (red), (b) sensible (black) and latent (red) heat fluxes measured with the EC system and gap-filled using a bulk formula (see Sect. 2.2.1 and Mammarella et al., 2015, for details), (c) wind speed, (d) wind direction, (e) daily rainfall, (f) incoming shortwave radiation and (g) effective heat flux measured at the measurement raft. Time ticks represent midnight and the vertical black line the start of the lake mixing period.

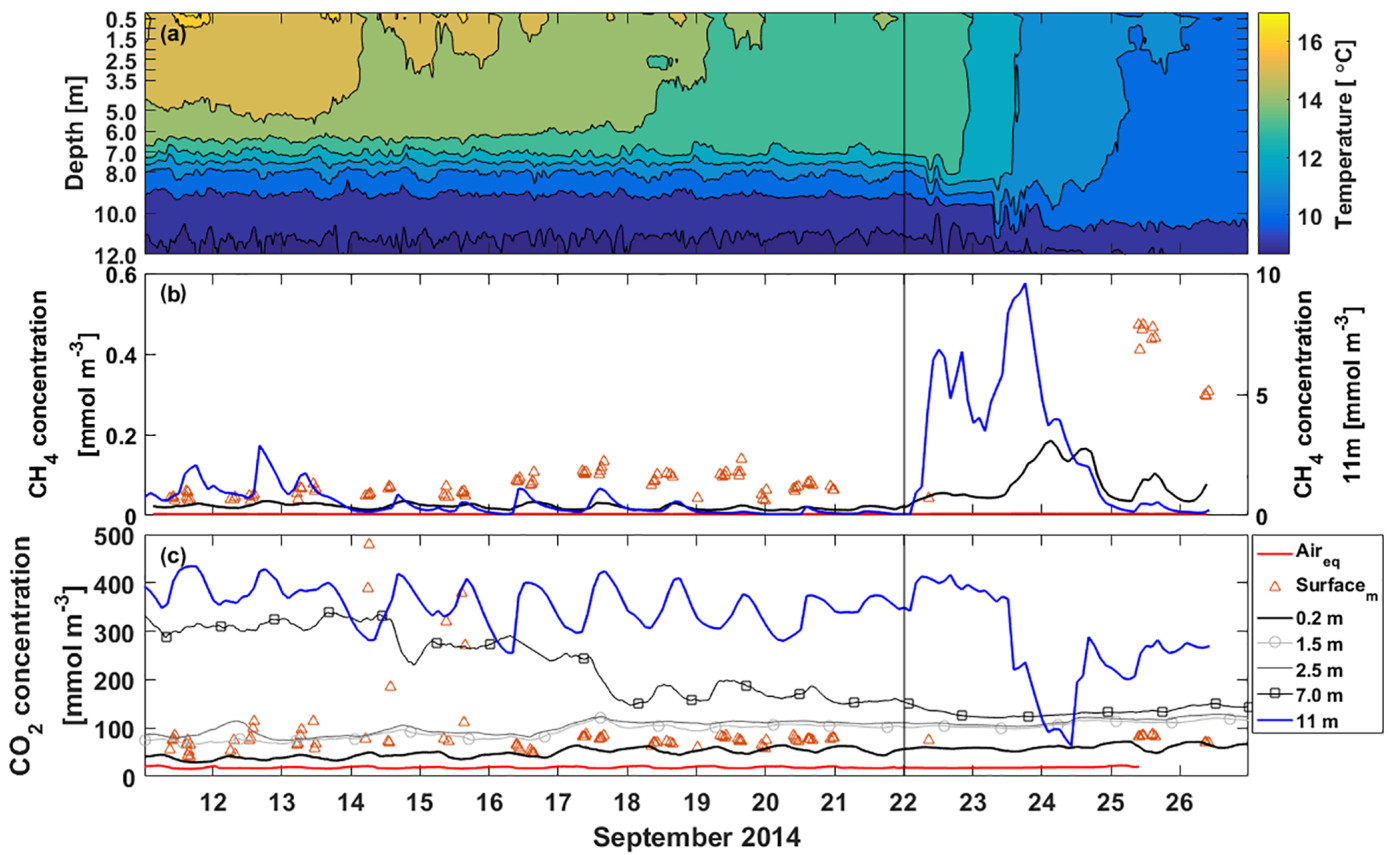

Figure 3. Half-hour averages of (a) temperature, (b) $\mathrm{CH}_{4}$ concentration and (c) $\mathrm{CO}_{2}$ concentration in the water column at different depths The red line is the equilibrium concentration of $\mathrm{CH}_{4}$ and $\mathrm{CO}_{2}$ at the surface in subplots (b) and (c), respectively. The orange triangles are manual headspace samples taken from the surface water at chamber measurement locations. Time ticks represent midnight and the vertical black line the start of the lake mixing period. Note that $\mathrm{CH}_{4}$ concentration at $11 \mathrm{~m}$ depth (blue line) is read from the right $y$ axis. 
22 September. Mixing reached $11 \mathrm{~m}$ depth in the end of the measurement campaign on 25 September but did not yet mix the bottom waters. During the mixing period sunrise was at $06: 15$ and sunset at 18:15.

\subsection{Water column gas concentration profiles}

\subsection{1 $\mathrm{CH}_{4}$ concentration profile}

During the stratified period $\mathrm{CH}_{4}$ concentration according to the automatic measurements at the surface was small, only around $0.02 \mathrm{mmol} \mathrm{m}^{-3}$ (Fig. 3b). Manual measurements, on the other hand, show surface water concentrations of $0.07 \mathrm{mmol} \mathrm{m}^{-3}$ on average during the stratified period. Manual $\mathrm{CH}_{4}$ concentration measurements were always higher than automatic measurements, which might be caused by insufficient equilibration time for $\mathrm{CH}_{4}$ in the automatic measurement system or by spatial variation only caught by manual measurements. At $11 \mathrm{~m}$ depth $\mathrm{CH}_{4}$ concentration was almost 10 times higher than at the surface. Diel variation of $\mathrm{CH}_{4}$ concentration at $11 \mathrm{~m}$ could be caused by lake-side cooling and convection or, more likely, by internal waves (Stepanenko et al., 2016), triggering the lake-bottom $\mathrm{CH}_{4}$-rich sediments.

On 22 September, thermocline tilting due to high wind speed caused a rapid increase in $11 \mathrm{~m} \mathrm{CH}_{4}$ concentration and the concentration reached its maximum of $9.6 \mathrm{mmol} \mathrm{m}^{-3}$ on 24 September. $\mathrm{CH}_{4}$ accumulation near the bottom usually happens in the anoxic conditions in late autumn (Stepanenko et al., 2016). $\mathrm{CH}_{4}$ concentration at $11 \mathrm{~m}$ depth was still three times lower than the maximum concentration found in Stepanenko et al. (2016) in late September and 2 times lower than found at $12 \mathrm{~m}$ depth in Miettinen et al. (2015) in September. A clear increase in $\mathrm{CH}_{4}$ surface water concentration is seen on 23 September due to upwelling and concentration up to $0.19 \mathrm{mmol} \mathrm{m}^{-3}$ was measured with the automatic system on 24 September. Manual measurements show concentrations up to $0.47 \mathrm{mmol} \mathrm{m}^{-3}$ on 25 September.

\subsection{2 $\mathrm{CO}_{2}$ concentration profile}

$\mathrm{CO}_{2}$ concentration at the surface was $47 \mathrm{mmol} \mathrm{m}^{-3}$ on average as measured with the automatic system during the stratified period, while manual measurements show $\mathrm{CO}_{2}$ concentration of $110 \mathrm{mmol} \mathrm{m}^{-3}$ at the water surface on average, similar to Miettinen et al. (2015) (Fig. 3c). On 14 September, surface layer mixing reached $7 \mathrm{~m}$ depth and brought $\mathrm{CO}_{2}$ rich water from deeper waters to the surface causing a drop in $\mathrm{CO}_{2}$ concentration at $7 \mathrm{~m}$ depth and manual samples show a rapid increase in the surface water concentration. Similar occasions on 16 and 17 September induced further decrease in $\mathrm{CO}_{2}$ concentration at $7 \mathrm{~m}$ depth and also an increase in the surface water $\mathrm{CO}_{2}$ concentration. After 16 September, the automatic and manual $\mathrm{CO}_{2}$ concentration measurements agree better with each other, as the average difference be- tween the measured concentrations decreases from 114 to $16 \mathrm{mmol} \mathrm{m}^{-3} \cdot \mathrm{CO}_{2}$ is more soluble in water than $\mathrm{CH}_{4}$ and thus equilibration time of $40 \mathrm{~min}$ should be enough for automatic $\mathrm{CO}_{2}$ measurements, and two different automatic systems compared well with each other on $\mathrm{CO}_{2}$ concentration at the surface (results not shown). We thereby conclude the difference between automatic and manual $\mathrm{CO}_{2}$ concentration measurements to be caused by spatial variation rather than the measurement system. We point out, however, that choosing the measurement method as well as the measurement spot has an effect on the observed concentrations and thus fluxes calculated with the BLM, as a larger concentration difference between the water surface and air would result in a larger flux in general (Eq. 2). $\mathrm{CO}_{2}$ concentration at $11 \mathrm{~m}$ depth was 10 times higher than at the surface and comparable to those measured in Miettinen et al. (2015) at $12 \mathrm{~m}$ depth. Diel variation observed in $\mathrm{CO}_{2}$ concentration at $11 \mathrm{~m}$ could be caused by either lake-side cooling and convection or by internal waves (Stepanenko et al., 2016).

Decreasing $\mathrm{CO}_{2}$ concentration from 390 to $63 \mathrm{mmol} \mathrm{m}^{-3}$ at $11 \mathrm{~m}$ depth observed on 23-24 September was probably due to upwelling. However, this amount of upwelling was not enough to cause a notable increase in the surface water $\mathrm{CO}_{2}$ concentration since $\mathrm{CO}_{2}$ concentration difference between the bottom and the surface is not as drastic as that of $\mathrm{CH}_{4}$, and the gas gets diluted in a large water volume on its way to the surface.

\section{3 $\mathrm{CH}_{4}$ flux comparison}

$\mathrm{CH}_{4}$ fluxes during the stratified period were small (less than $2 \mathrm{nmol} \mathrm{m}^{-2} \mathrm{~s}^{-1}$ ), estimated both with EC and BLM (Fig. 4). The EC fluxes during the stratified period were close to the detection limit (approximately $0.12 \mathrm{nmol} \mathrm{m}^{-2} \mathrm{~s}^{-1}$ for daily median flux) and are thus partly uncertain. FC fluxes were highest, reaching a maximum daily median flux of $4 \mathrm{nmol} \mathrm{m}^{-2} \mathrm{~s}^{-1}$ on 12 September. The median of all FC $\mathrm{CH}_{4}$ flux measurements during the stratified period still remained at $1.77_{-0.78}^{+0.82} \mathrm{nmol} \mathrm{m}^{-2} \mathrm{~s}^{-1}$ (where the lower and upper limits represent the 25th and 75th percentiles, respectively, Table 1). Median $\mathrm{CH}_{4}$ flux according to all three methods during the stratified period was considerably lower than $4 \mathrm{nmol} \mathrm{m}^{-2} \mathrm{~s}^{-1}$ reported in Miettinen et al. (2015), who used BLM with $k$ calculated from FC measurements, for Lake Kuivajärvi in autumn 2011 and 2012.

During the stratified period, EC and BLM with $k_{\mathrm{TE}}$ model show no statistical difference between daytime and nighttime fluxes, whereas BLM fluxes measured with $k_{\mathrm{HE}}$ and $k_{\mathrm{CC}}$ are slightly higher during night-time than daytime (Table 1). As the $\mathrm{CH}_{4}$ concentration difference $\left(\Delta\left[\mathrm{CH}_{4}\right]\right)$ between the surface water and air is lower in night-time than daytime, higher night-time fluxes are caused by gas transport coefficients $k_{\mathrm{HE}}$ and $k_{\mathrm{CC}}$ giving highest values at night-time (Fig. A1). The differences between daytime and night-time fluxes still remain lower than $0.3 \mathrm{nmol} \mathrm{m}^{-2} \mathrm{~s}^{-1}$. FC fluxes, 
Table 1. Median of all $\mathrm{CH}_{4}$ fluxes and average daytime and night-time $\mathrm{CH}_{4}$ fluxes during lake stratification and mixing periods using different measurement methods. Results of Mann-Whitney $U$ test comparing differences between daytime and night-time fluxes are given in $U$ test column. Note that FC fluxes are averaged also over different measurement spots. Mixing period did not include enough FC measurements for this analysis. Uncertainties are given as 25 th and 75 th percentiles for median fluxes and as standard errors for the flux averages.

\begin{tabular}{|c|c|c|c|c|}
\hline \multirow[t]{2}{*}{ Stratified period } & \multicolumn{4}{|c|}{$\mathrm{CH}_{4}$ flux $\left(\mathrm{nmol} \mathrm{m}^{-2} \mathrm{~s}^{-1}\right)$} \\
\hline & All & Day & Night & $U$ test \\
\hline BLM $k_{\mathrm{HE}}$ & $0.21_{-0.06}^{+0.12}$ & $0.177( \pm 0.005)$ & $0.431( \pm 0.008)$ & $h=1, p=0.0004$ \\
\hline $\mathrm{BLM} k_{\mathrm{TE}}$ & $0.26_{-0.13}^{+0.16}$ & $0.370( \pm 0.011)$ & $0.439( \pm 0.007)$ & $h=0$ \\
\hline $\mathrm{BLM} k_{\mathrm{CC}}$ & $0.12_{-0.04}^{+0.05}$ & $0.128( \pm 0.003)$ & $0.186( \pm 0.004)$ & $h=1, p=0.02$ \\
\hline $\mathrm{EC}$ & $0.51_{-0.34}^{+0.34}$ & $0.41( \pm 0.04)$ & $0.34( \pm 0.04)$ & $h=0$ \\
\hline $\mathrm{FC}$ & $1.77_{-0.78}^{+0.34}$ & $2.4( \pm 0.3)$ & $1.1( \pm 0.2)$ & $h=1, p=0.002$ \\
\hline \multirow[t]{2}{*}{ Mixing period } & \multicolumn{4}{|c|}{$\mathrm{CH}_{4}$ flux $\left(\mathrm{nmol} \mathrm{m}^{-2} \mathrm{~s}^{-1}\right)$} \\
\hline & All & Day & Night & $U$ test \\
\hline BLM $k_{\mathrm{HE}}$ & $4.34_{-3.35}^{+9.81}$ & $7.1( \pm 0.6)$ & $6.6( \pm 0.5)$ & $h=0$ \\
\hline $\mathrm{BLM} k_{\mathrm{TE}}$ & $4.73_{-3.15}^{+9.41}$ & $7.7( \pm 0.6)$ & $7.1( \pm 0.5)$ & $h=0$ \\
\hline $\mathrm{BLM} k_{\mathrm{CC}}$ & $1.65_{-1.04}^{+5.50}$ & $3.7( \pm 0.3)$ & $2.8( \pm 0.2)$ & $h=0$ \\
\hline $\mathrm{EC}$ & $4.80_{-2.28}^{+3.34}$ & $5.9( \pm 0.3)$ & $5.0( \pm 0.4)$ & $h=1, p=0.02$ \\
\hline
\end{tabular}

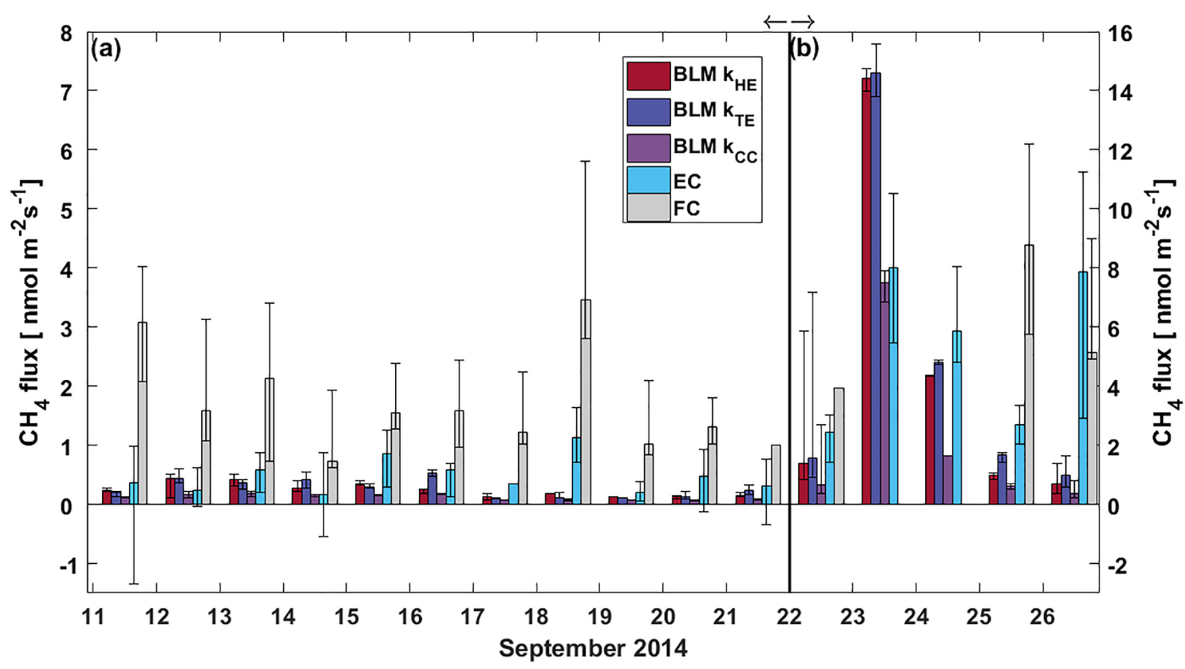

Figure 4. Daily median $\mathrm{CH}_{4}$ flux from BLM, EC and FC methods. The black whiskers indicate the 25th and 75th percentiles, respectively. The vertical black line represents the start of the lake mixing period. Fluxes during (a) the stratified period (11-21 September) are read from the left and (b) mixing period fluxes (22-26 September) from the right $y$ axis.

however, are higher during daytime, when the concentration difference also has its maximum value.

After the mixing started on 22 September, daily median $\mathrm{CH}_{4}$ fluxes increased rapidly from 1.5 to even $15 \mathrm{nmol} \mathrm{m}^{-2} \mathrm{~s}^{-1}$ in one day due to effective mixing and gas transport from deeper waters to the surface. This increase is clearly visible in both EC and BLM fluxes, although BLM flux calculated with $k_{\mathrm{CC}}$ remains lower than other BLM fluxes and is closest to EC median flux on 23 September. The flux peak in the beginning of the mixing period was over 2-fold higher compared to the $6 \mathrm{nmol} \mathrm{m}^{-2} \mathrm{~s}^{-1}$ reported in Miettinen et al. (2015), probably due to rougher weather conditions during our field campaign. Ojala et al. (2011), on the other hand, report high $\mathrm{CH}_{4}$ emissions $\left(6 \mathrm{nmol} \mathrm{m}^{-2} \mathrm{~s}^{-1}\right)$ after heavy rain events. Rain on 22 September could have also played a role here, enhancing the lateral transport from the catchment to the lake (Ojala et al., 2011; Rantakari and Kortelainen, 2005). However, in comparison to the situation described by Ojala et al. (2011), the rain episode in Lake Kuivajärvi was very short in duration.

During the mixing period, EC measurements show a diurnal pattern in $\mathrm{CH}_{4}$ flux with higher daytime than night-time 
Table 2. Linear fit $y=a x+b$ parameters for comparison between EC and BLM fluxes according to different models for $k$, and between EC and FC, when EC flux estimates were on the $x$ axis. Uncertainties are given by the standard errors of the parameters. The last column gives the results of Mann-Whitney $U$ test for each method compared with EC. The comparison was made using daily median fluxes.

\begin{tabular}{llrrccl}
\hline & Method & $a$ & $\begin{array}{r}b \\
\left(\mathrm{nmol} \mathrm{m}^{-2} \mathrm{~s}^{-1}\right)\end{array}$ & \multicolumn{2}{c}{$\begin{array}{c}\text { RMSE } \\
\left(\mathrm{nmol} \mathrm{m}^{-2} \mathrm{~s}^{-1}\right)\end{array}$} & $U$ test \\
\hline $\mathrm{CH}_{4}$ & BLM $k_{\mathrm{HE}}$ & $0.9 \pm 0.2$ & $-0.3 \pm 0.8$ & 0.50 & 2.62 & $h=1, p=8 \times 10^{-5}$ \\
& BLM $k_{\text {TE }}$ & $1.0 \pm 0.2$ & $-0.3 \pm 0.8$ & 0.53 & 2.58 & $h=1, p=0.0007$ \\
& BLM $k_{\mathrm{CC}}$ & $0.5 \pm 0.1$ & $-0.2 \pm 0.4$ & 0.48 & 1.38 & $h=1, p=1 \times 10^{-8}$ \\
& FC & $2.0 \pm 0.5$ & $1.1 \pm 0.5$ & 0.62 & 1.35 & $h=1, p=3 \times 10^{-8}$ \\
\hline $\mathrm{CO}_{2}$ & BLM $k_{\mathrm{HE}}$ & $0.6 \pm 0.3$ & $0.3 \pm 0.2$ & 0.27 & 0.58 & $h=1, p=0.02$ \\
& BLM $k_{\text {TE }}$ & $0.6 \pm 0.3$ & $0.4 \pm 0.2$ & 0.26 & 0.59 & $h=1, p=6 \times 10^{-5}$ \\
& BLM $k_{\mathrm{CC}}$ & $0.3 \pm 0.1$ & $0.2 \pm 0.1$ & 0.20 & 0.30 & $h=1, p=0.01$ \\
& FC & $0.2 \pm 0.2$ & $0.50 \pm 0.12$ & 0.13 & 0.32 & $h=1, p=0.002$ \\
\hline
\end{tabular}

fluxes, as was found in Keller and Stallard (1994), Bastviken et al. (2004) and Bastviken et al. (2010). BLM measurements do not show a statistical difference between daytime and night-time (Table 1). Higher daytime fluxes are expected due to higher wind speed and enhanced shear during the afternoon (Bastviken et al., 2010) as well as upwelling of $\mathrm{CH}_{4}$ from deeper layer (Fig. A2d). We find a lower concentration difference, $\Delta\left[\mathrm{CH}_{4}\right]$, during night-time. This may be caused by higher oxidation rate in dark, which lowers $\mathrm{CH}_{4}$ concentration in the water, and thus also the concentration difference (Mitchell et al., 2005; Dumestre et al., 1999). During daytime solar radiation, the oxidation rate would then be lower, resulting in an increase in water $\mathrm{CH}_{4}$ concentration towards the afternoon. Another possible explanation for larger concentration difference $\Delta\left[\mathrm{CH}_{4}\right]$ in the afternoon, in addition to $\mathrm{CH}_{4}$ feeding from the deeper waters and lower oxidation rate, is enhanced resuspension from the sediments in the littoral zone during periods of high wind speed (Bussmann, 2005). EC and BLM fluxes by $k_{\mathrm{HE}}$ and $k_{\mathrm{TE}}$ are also similar in magnitude $\left(5.9 \pm 0.3,7.1 \pm 0.6\right.$ and $7.7 \pm 0.6 \mathrm{nmol} \mathrm{m}^{-2} \mathrm{~s}^{-1}$ daytime averages, respectively), whereas $k_{\mathrm{CC}}$ gives clearly lower fluxes $\left(3.7 \pm 0.3 \mathrm{nmol} \mathrm{m}^{-2} \mathrm{~s}^{-1}\right.$ daytime average, Table 1). Keller and Stallard (1994), Bastviken et al. (2004) and Bastviken et al. (2010) also report highest daytime fluxes for $\mathrm{CH}_{4}$ probably caused by more effective turbulent transfer during daytime, while Podgrajsek et al. (2014b) report higher night-time fluxes and suggest it to be caused by water-side convection. However, we find that both surface water concentration changes and more effective daytime gas transfer are likely explanations to the higher daytime $\mathrm{CH}_{4}$ fluxes in Lake Kuivajärvi.

Linear fit parameters for the EC and BLM flux comparison for $\mathrm{CH}_{4}$ show that $k_{\mathrm{TE}}\left(r^{2}=0.53\right)$ and $k_{\mathrm{HE}}\left(r^{2}=0.50\right)$ were comparable to EC measurements, but $k_{\mathrm{CC}}\left(r^{2}=0.48\right)$ resulted in clearly lower fluxes than EC measurements $(p<$ 0.05 , Table 2). Ebullition is not an important gas transport mechanism in the EC footprint area as found in Stepanenko et al. (2016) and thus BLM including only diffusive gas flux is expected to give results close to EC. A similar result with $k_{\mathrm{CC}}$ giving the lowest flux estimate was also found in Schubert et al. (2012), where EC and FC methods gave 8 and 7 times higher cumulative fluxes than BLM with $k_{\mathrm{CC}}$. Also, Blees et al. (2015) report seasonal changes in $\mathrm{CH}_{4}$ flux due to cooling and changes in buoyancy flux. This further encourages to prefer up-to-date $k$ models instead of $k_{\mathrm{CC}}$ in $\mathrm{CH}_{4}$ flux estimates. $\mathrm{FC}$ measured daily median $\mathrm{CH}_{4}$ fluxes 2 times higher than $\mathrm{EC}(p<0.05$, Table 2$)$, as was also observed in Eugster et al. (2011), and thus gave highest flux estimates from all three methods. A reason behind the result might be that these low fluxes are very difficult to detect with the EC method, since the $\mathrm{CH}_{4}$ fluxes were very close to the detection limit of the EC measurement system. Higher fluxes during the mixing period could have been more suitable for a comparison between the two methods. Podgrajsek et al. (2014a) did not find systematically higher fluxes with EC or FC and found quite good agreement between these two methods for $\mathrm{CH}_{4}$ fluxes. The EC method has a larger source area (flux footprint) than FC method, which might also affect the flux. Windy conditions during the mixing period could have made the comparison better, but manual FC measurements are difficult to do during high wind and rough weather conditions.

In addition to comparison between FC and EC measurements on a temporal scale, spatial variation of $\mathrm{CH}_{4}$ flux within the EC footprint area was also studied with floating chambers at different parts of the lake during the stratified period 11-21 September 2014. The measurement spots were chosen upwind from the measurement raft to ensure being within the EC footprint area. Results are shown in Fig. 5, where the median of FC measurements at different spots are compared with the median of simultaneous EC measurements.

Measurement points N3 and N4 showed slightly higher median $\mathrm{FC} \mathrm{CH}_{4}$ fluxes than elsewhere, although the 25th and 75 th percentiles fall within the same range in all locations (Fig. 5a). Since the two measurement locations are of different depth and other locations measure similar fluxes com- 

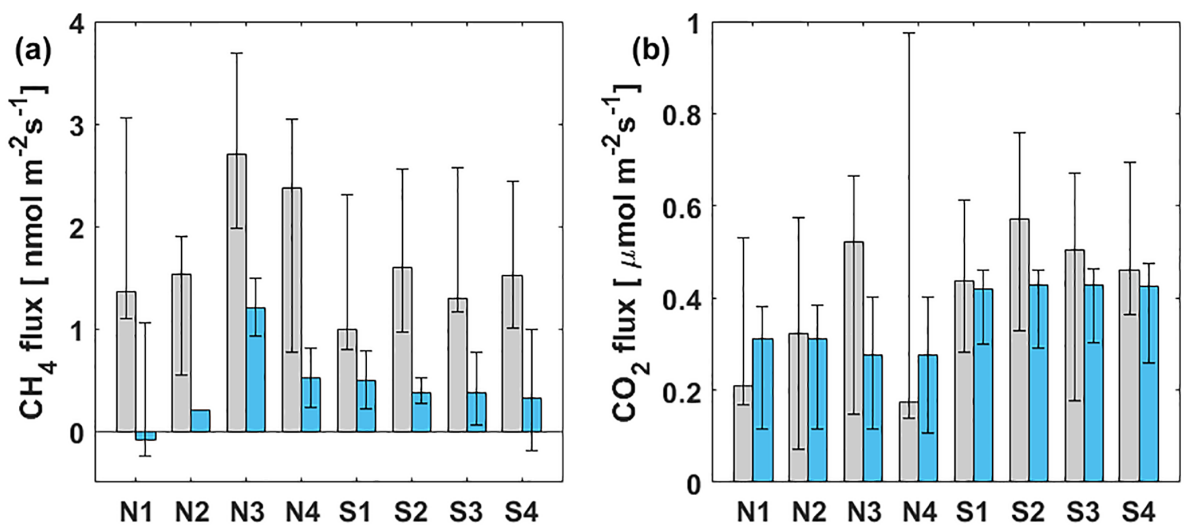

Figure 5. Median (a) $\mathrm{CH}_{4}$ and (b) $\mathrm{CO}_{2} \mathrm{FC}$ fluxes (grey bars) at different measurement spots and median of simultaneous EC measurements (blue bars) during lake stratification. Black whiskers represent the 25 th and 75 th percentiles.

pared to each other, we cannot make any conclusions about depth or wind direction dependencies. EC measurements do not show any difference in $\mathrm{CH}_{4}$ fluxes measured from the south side or the north side of the measurement raft. FC measured $\mathrm{CH}_{4}$ fluxes were systematically higher than simultaneous EC fluxes, independent from the measurement location.

\section{$3.4 \mathrm{CO}_{2}$ flux comparison}

$\mathrm{CO}_{2}$ flux was small (below $1 \mu \mathrm{mol} \mathrm{m} \mathrm{m}^{-2} \mathrm{~s}^{-1}$ ) at the beginning of the measurement campaign and similar to those reported in Miettinen et al. (2015), Mammarella et al. (2015) and Heiskanen et al. (2014) due to low wind speeds and thermal stratification of the lake (Fig. 6). Negative daily median EC fluxes on 11, 12 and 14 September were not statistically different from zero $(p<0.05$, tested with Mann-Whitney $U$ test) and denote very small fluxes close to the detection limit of the measurement system $\left(0.12 \mu \mathrm{mol} \mathrm{m}^{-2} \mathrm{~s}^{-1}\right)$, rather than uptake, which would be very unlikely in September in a boreal lake.

In the stratified period, BLM with $k_{\mathrm{TE}}$ and FC methods results in a similar diurnal pattern with higher fluxes detected during daytime than night-time, while BLM with $k_{\mathrm{TE}}$ shows the opposite and EC and BLM with $k_{\mathrm{CC}}$ show no statistical difference between daytime and night-time fluxes (Table 3 ). Low BLM flux in the daytime $\left(0.305 \pm 0.009 \mu \mathrm{mol} \mathrm{m}^{-2} \mathrm{~s}^{-1}\right.$ on average with $k_{\mathrm{HE}}$ model) is probably caused by photosynthetic activity of algae in the lake that reduces the $\mathrm{CO}_{2}$ concentration difference between air and water $\left(\Delta\left[\mathrm{CO}_{2}\right]\right)$ right after sunrise (Fig. A1d, Table 3). Also, the convective term $\left(C_{2} w_{*}\right)$ in $k_{\mathrm{HE}}$ is zero during daytime, when the lake is heating due to higher air temperature, resulting in a lower $k_{\mathrm{HE}}$ (Fig. A1a). Higher flux during nighttime $\left(0.410 \pm 0.008\right.$ on average with $k_{\mathrm{HE}}$ model $)$ is probably caused by turbulence created by waterside cooling (Heiskanen et al., 2014). This is seen in Fig. A1a as the convective term $C_{2} w_{*}$ increases towards night-time causing higher gas transfer coefficient $k_{\mathrm{HE}}$ and thus higher flux as well.
Podgrajsek et al. (2015) argued that the main driver for enhanced night-time gas exchange is convection, and they did not find a correlation with the concentration difference $\Delta\left[\mathrm{CO}_{2}\right]$. However, we find that $\Delta\left[\mathrm{CO}_{2}\right]$ also increases during night-time due to the absence of algal photosynthesis. BLM by $k_{\mathrm{TE}}$ gives highest fluxes at noon, when friction velocity also gains its maximum value (Fig. A1c), even though $\Delta\left[\mathrm{CO}_{2}\right]$ is at its minimum. In the absence of buoyancy term in daytime, the gas transfer velocity $k_{\mathrm{TE}}$ is solely composed of the shear term. The BLM flux by $k_{\mathrm{TE}}$ is thus also larger in the daytime $\left(0.545 \pm 0.014 \mu \mathrm{mol} \mathrm{m}^{-2} \mathrm{~s}^{-1}\right.$ on average, Table 3) despite the lower $\Delta\left[\mathrm{CO}_{2}\right]$, and night-time flux $\left(0.396 \pm 0.010 \mu \mathrm{mol} \mathrm{m}^{-2} \mathrm{~s}^{-1}\right)$ is $27 \%$ smaller than the daytime flux during the stratified period. Water friction velocity, that was used in $k_{\mathrm{TE}}$, was calculated from direct EC measurements in the air (Eq. 6). Friction velocity calculated from wind speed measurements (with a drag coefficient 0.001 for a water surface) instead of direct $u_{* \mathrm{a}}$ measurements gave similar diurnal variation to model $k_{\mathrm{HE}}$ (data not shown) but resulted in a lower $u_{* \mathrm{w}}$ than with direct $u_{* \mathrm{a}}$ measurements. BLM with $k_{\mathrm{TE}}$ could give better results with direct turbulence measurements in the water. The buoyancy term $(\beta)$ in $k_{\mathrm{TE}}$ is low compared to the shear term $\left(u_{*}^{3} /(\kappa z)\right)$ even during night-time (Fig. A1c). EC and BLM with $k_{\mathrm{CC}}$ methods do not show any diurnal variation for $\mathrm{CO}_{2}$ exchange over the lake when the lake is stratified. Vesala et al. (2006) did not detect diurnal variation in $\mathrm{CO}_{2} \mathrm{EC}$ flux in September either over a small humic lake in Finland with fluxes usually under $1 \mu \mathrm{mol} \mathrm{m}{ }^{-2} \mathrm{~s}^{-1}$ during the stratified period. Overall, $k_{\mathrm{HE}}$ and EC measurements agree well on the magnitude of $\mathrm{CO}_{2}$ flux during daytime, while $\mathrm{FC}$ measured $\mathrm{CO}_{2}$ fluxes closest to $\mathrm{EC}$ during night-time in the stratified period.

The flux increased almost 3-fold when the lake started mixing with higher wind speeds and was larger $\left(3 \mu \mathrm{mol} \mathrm{m}{ }^{-2} \mathrm{~s}^{-1}\right)$ than reported in other studies from Lake Kuivajärvi (less than $2 \mu \mathrm{mol} \mathrm{m}{ }^{-2} \mathrm{~s}^{-1}$; Miettinen et al., 2015; Mammarella et al., 2015). EC, on the other hand, measured 
Table 3. Median of all $\mathrm{CO}_{2}$ fluxes and average daytime and night-time $\mathrm{CO}_{2}$ fluxes during lake stratification and mixing periods using different measurement methods. Results of Mann-Whitney $U$ test comparing differences between daytime and night-time fluxes are given in $U$ test column. Note that FC fluxes are averaged also over different measurement spots. Mixing period did not include enough FC measurements for this analysis. Uncertainties are given as 25th and 75th percentiles for median fluxes and as standard errors for the flux averages.

\begin{tabular}{|c|c|c|c|c|}
\hline \multirow[t]{2}{*}{ Stratified period } & \multicolumn{4}{|c|}{$\mathrm{CO}_{2}$ flux $\left(\mu \mathrm{mol} \mathrm{m} \mathrm{m}^{-2} \mathrm{~s}^{-1}\right)$} \\
\hline & All & Day & Night & $U$ test \\
\hline $\mathrm{BLM} k_{\mathrm{HE}}$ & $0.31_{-0.08}^{+0.17}$ & $0.305( \pm 0.009)$ & $0.410( \pm 0.008)$ & $h=1, p=0.0008$ \\
\hline $\mathrm{BLM} k_{\mathrm{TE}}$ & $0.44_{-0.11}^{+0.13}$ & $0.545( \pm 0.014)$ & $0.396( \pm 0.010)$ & $h=1, p=0.01$ \\
\hline $\mathrm{BLM} k_{\mathrm{CC}}$ & $0.19_{-0.04}^{+0.05}$ & $0.201( \pm 0.004)$ & $0.180( \pm 0.004)$ & $h=0$ \\
\hline $\mathrm{EC}$ & $0.35_{-0.69}^{+0.44}$ & $0.31( \pm 0.04)$ & $0.28( \pm 0.08)$ & $h=0$ \\
\hline FC & $0.50_{-0.27}^{+0.20}$ & $0.62( \pm 0.08)$ & $0.29( \pm 0.04)$ & $h=1, p=0.01$ \\
\hline \multirow[t]{2}{*}{ Mixing period } & \multicolumn{4}{|c|}{$\mathrm{CO}_{2}$ flux $\left(\mu \mathrm{mol} \mathrm{m} \mathrm{m}^{-2} \mathrm{~s}^{-1}\right)$} \\
\hline & All & Day & Night & $U$ test \\
\hline $\mathrm{BLM} k_{\mathrm{HE}}$ & $1.80_{-0.65}^{+0.86}$ & $2.15( \pm 0.06)$ & $1.43( \pm 0.05)$ & $h=1, p=0.0002$ \\
\hline $\mathrm{BLM} k_{\mathrm{TE}}$ & $2.15_{-0.91}^{+0.05}$ & $2.37( \pm 0.06)$ & $1.54( \pm 0.05)$ & $h=1, p=5 \times 10^{-5}$ \\
\hline $\mathrm{BLM} k_{\mathrm{CC}}$ & $0.73_{-0.21}^{+0.91}$ & $1.11( \pm 0.04)$ & $0.58( \pm 0.02)$ & $h=1, p=7 \times 10^{-6}$ \\
\hline $\mathrm{EC}$ & $1.09_{-0.95}^{+0.74}$ & $1.3( \pm 0.2)$ & $0.88( \pm 0.14)$ & $h=0$ \\
\hline
\end{tabular}

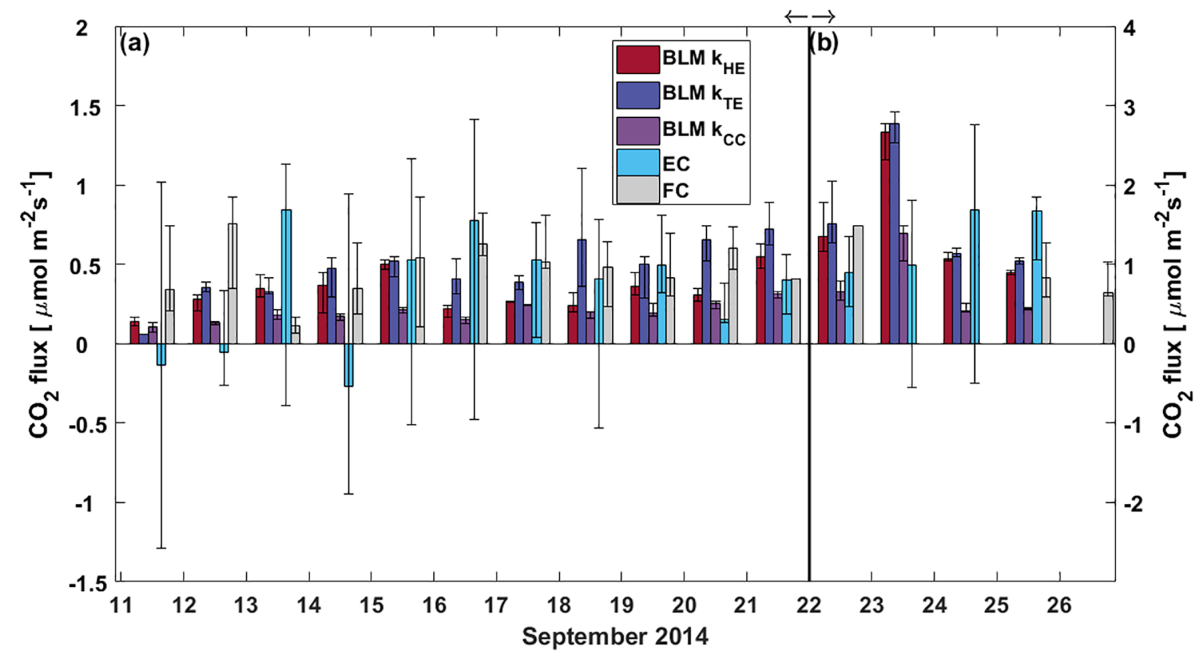

Figure 6. Daily median $\mathrm{CO}_{2}$ flux from BLM, EC and FC methods. The black whiskers indicate the 25th and 75th percentiles, respectively. The vertical black line represents the start of the lake mixing period. Fluxes during (a) the stratified period (11-21 September) are read from the left and (b) mixing period fluxes (22-26 September) from the right $y$ axis.

daily median $\mathrm{CO}_{2}$ flux less than $2 \mu \mathrm{mol} \mathrm{m}{ }^{-2} \mathrm{~s}^{-1}$, as reported in other studies.

Average daytime $\mathrm{CO}_{2}$ fluxes were $1.3 \pm 0.2,2.15 \pm 0.06$, $2.37 \pm 0.06$ and $1.11 \pm 0.04 \mu \mathrm{mol} \mathrm{m}^{-2} \mathrm{~s}^{-1}$ with the EC method and BLM by $k_{\mathrm{HE}}, k_{\mathrm{TE}}$ and $k_{\mathrm{CC}}$, respectively. Nighttime average fluxes were notably smaller, as $0.88 \pm 0.14$, $1.43 \pm 0.05,1.54 \pm 0.05$ and $0.58 \pm 0.02 \mu \mathrm{mol} \mathrm{m}^{-2} \mathrm{~s}^{-1}$ with the EC method and BLM by $k_{\mathrm{HE}}, k_{\mathrm{TE}}$ and $k_{\mathrm{CC}}$, respectively (Table 3). Highest flux according to BLM with all three $k$ models was measured at noon, when wind speeds are highest. Shear terms $C_{1} U$ and $u_{*}^{3} /(\kappa z)$ in $k_{\mathrm{HE}}$ and $k_{\mathrm{TE}}$ models, respectively, have diurnal variations with highest values at noon as well (Fig. A2a and c), which results in higher daytime BLM fluxes with $k_{\mathrm{HE}}$ and $k_{\mathrm{TE}}$. BLM by $k_{\mathrm{CC}}$, however, shows considerably lower fluxes than $k_{\mathrm{HE}}$ and $k_{\mathrm{TE}}$ both during daytime and night-time on average. Higher fluxes during daytime than night-time in the mixing period are expected due to enhanced gas transfer during stronger winds in the daytime. The buoyancy term $\beta$ in $k_{\mathrm{TE}}$ is still almost a magnitude smaller than the shear term and does not influence the $k_{\mathrm{TE}}$ much, even during lake mixing (Fig. A2c). The maximum and minimum concentration differences $\Delta\left[\mathrm{CO}_{2}\right]$ were 
1.4 to 1.6 times higher during the mixing period than in the stratified period. This may be caused by upwelling of $\mathrm{CO}_{2}$ from deep waters to the surface during the mixing period and more effective algal photosynthesis during the stratified period. This indicates that selectively using only daytime gas concentration measurements in BLMs systematically biases the estimates of the long-term carbon budget.

Linear fit parameters for the comparison of BLM and FC methods with EC measurements show that $k_{\mathrm{TE}}\left(r^{2}=0.26\right)$ and $k_{\mathrm{HE}}\left(r^{2}=0.27\right)$ give the best results when compared with EC ( $60 \%$ of the measured EC flux). $\mathrm{BLM} \mathrm{CO}_{2}$ flux based on $k_{\mathrm{CC}}$ was clearly underestimated, being only about $30 \%$ of the measured EC flux $\left(r^{2}=0.20\right)$ and FC fluxes were also generally lower than EC $\left(20 \%, r^{2}=0.13\right.$, Table 2). The same result of $k_{\mathrm{CC}}$ giving lower fluxes than EC was found also in other studies (e.g. Heiskanen et al., 2014; Mammarella et al., 2015; Podgrajsek et al., 2015) and the use of this model in global carbon budget estimates may therefore be questionable (e.g. Raymond et al., 2013). During lake stratification, $k_{\mathrm{CC}}$ gives the general flux level quite well, while during lake mixing and rain events it is clearly lower than the other measured fluxes. However, on an annual scale, these special occasions might contribute significantly to the $\mathrm{CH}_{4}$ and $\mathrm{CO}_{2}$ budgets (Ojala et al., 2011; Podgrajsek et al., 2014a; Miettinen et al., 2015) and should be noted in upscaled flux estimates.

During the stratified period, $\mathrm{CO}_{2}$ fluxes were almost always higher when measured with FC than simultaneous EC measurements, as also found in Eugster et al. (2003) and Podgrajsek et al. (2014a) (statistical significance tested with Mann-Whitney $U$ test, $p<0.05$ ), although daily median values were, on average, higher when measured with EC than FC (Table 2). Lower daily median FC fluxes might thus result from discontinuous FC measurements missing important episodic flux events, as suggested by Podgrajsek et al. (2014a). However, from the north side of the measurement raft (measurement spots N1-N4), FC fluxes do not differ statistically from $\mathrm{EC} \mathrm{CO}_{2}$ fluxes.

The FC measurements did not show spatial variation in $\mathrm{CO}_{2}$ flux but there is a clear difference between EC measurements from the south and north sides of the lake (tested with Mann-Whitney $U$ test, $p<0.05$ ) with approximately $0.1 \mu \mathrm{mol} \mathrm{m} \mathrm{m}^{-2} \mathrm{~s}^{-1}$ higher $\mathrm{CO}_{2}$ fluxes measured from the south than from north (Fig. 5b). The south side of the raft is shallower than the north side (Fig. 1a) and thus more prone for the mixing to reach bottom even during the stratified period. The EC footprint area of 100-300 m (Mammarella et al., 2015) from the raft reaches further to the shallow areas than the FC measurements that were done approximately $50 \mathrm{~m}$ south from the raft. EC is thus more likely to catch the higher gas fluxes resulting from upwelling of gas-rich waters from the bottom. Higher $\mathrm{CH}_{4}$ flux from the south side was not detected possibly due to $\mathrm{CH}_{4}$ oxidation in the water column into $\mathrm{CO}_{2}$. This oxidation would not increase the $\mathrm{CO}_{2}$ efflux, as $\mathrm{CH}_{4}$ flux is so much smaller than that of $\mathrm{CO}_{2}$. The footprint area north from the raft is over significantly deeper water and mixing from the deeper waters during stratified period is unlikely.

\section{Conclusions}

We found that all gas transfer velocity, $k$, models used in BLM calculation gave mainly lower flux estimates of both $\mathrm{CH}_{4}$ and $\mathrm{CO}_{2}$ compared to $\mathrm{EC}$, while $\mathrm{FC}$ measurements were mostly higher than EC. For $\mathrm{CH}_{4}$ fluxes, this difference between the FC and EC methods is probably caused by the fact that, during lake stratification, the measured fluxes were very small, close to the detection limit of the EC system. For $\mathrm{CO}_{2}$, there was no statistical difference between the FC and EC methods over the north side of the lake, and night-time average fluxes were almost the same with these two methods. Gas transfer velocity models by Tedford et al. (2014) $\left(k_{\mathrm{TE}}\right)$ and Heiskanen et al. (2014) $\left(k_{\mathrm{HE}}\right)$ showed very similar fluxes both for $\mathrm{CH}_{4}$ and $\mathrm{CO}_{2}$, and the $k$ model by Cole and Caraco (1998) $\left(k_{\mathrm{CC}}\right)$ resulted in clearly lower gas fluxes especially during the lake mixing period. A comparison between BLM and EC fluxes showed that, on average, the $k_{\mathrm{TE}}$ model is the most similar and the $k_{\mathrm{CC}}$ model the lowest, when compared to EC fluxes. For global upscaling, it would be preferable to use up-to-date $k$ models instead of $k_{\mathrm{CC}}$ to reduce the risk of systematic biases. The simple $k_{\mathrm{CC}}$ model underestimates the flux especially during special occasions of, for example, lake mixing and rain events, which may vastly contribute to the annual flux estimate.

During the stratified period, $\mathrm{CO}_{2}$ flux by $k_{\mathrm{TE}}$ showed higher daytime than night-time fluxes, opposite to other models, due to higher air friction velocity during daytime. This model could work better with direct friction velocity measurements in the water. The buoyancy term included in $k_{\mathrm{TE}}$ model was not significant compared to the shear term even in night-time, and does not affect the diurnal variation of the flux. $\mathrm{CO}_{2}$ concentration difference between the surface water and air was found to have a diurnal cycle with lower values during daytime, probably due to algal photosynthesis reducing surface water concentration of $\mathrm{CO}_{2}$. An opposite diurnal cycle was found for $\mathrm{CH}_{4}$ concentration difference with highest values reached in the afternoon. This might be due to $\mathrm{CH}_{4}$ feeding from the deeper waters, lower oxidation rate in daylight in the water column, or more effective lateral transport from the littoral zone during higher wind speeds in the daytime. As we observe a clear diurnal cycle in the concentration difference for both $\mathrm{CH}_{4}$ and $\mathrm{CO}_{2}$, it is important to note that using only daytime concentration (and wind speed) measurements for upscaling with BLM affects the resulting flux estimate.

Including the effect of lake cooling clearly improves the flux estimate both for $\mathrm{CH}_{4}$ and $\mathrm{CO}_{2}$, although these models are not as simple to use as wind-speed-based models. In the absence of an extensive measurement system, the use of e.g. 
bulk formulas for estimating latent and sensible heat fluxes for $k_{\mathrm{HE}}$ and $k_{\mathrm{TE}}$ would result in better flux estimates than the use of $k_{\mathrm{CC}}$. This would require an estimate for the depth of the actively mixing layer, light extinction coefficient, radiation data, and wind speed, as well as temperature and moisture differences between the air and water surface. With this information, it is possible to calculate the effective heat flux and buoyancy flux, after which estimating $k_{\mathrm{HE}}$ and $k_{\mathrm{TE}}$ is straightforward, keeping in mind that the water-side friction velocity for $k_{\mathrm{TE}}$ model may be estimated from wind speed measurements by scaling it with an appropriate drag coefficient.

FC measurements did not show a spatial variation in either $\mathrm{CH}_{4}$ or $\mathrm{CO}_{2}$ flux. $\mathrm{CO}_{2} \mathrm{EC}$ flux was clearly higher from the south side of the measurement raft than north, due to the shallower lake area within the EC footprint on the south side. This was not detected with $\mathrm{CH}_{4}$, possibly due to oxidation in the water column.

FC measurements are generally used for studying spatial variation, but our results suggest that $\mathrm{EC}$ measurements are also able to detect differences between different wind sectors. EC measurement systems are set up in one place, often on the shore or on a raft near the deepest parts of the lake to have a large footprint area for measurements. This is due to one of the limitations in the EC method, because it requires a homogeneous surface and favourable wind conditions but leads to possibly biased flux estimations, especially if flux is only measured over a particularly deep or shallow area not representative of the lake. The FC method is good for detecting spatial variation but has its limitations regarding temporal and spatial data coverage and challenging measurements in windy and wavy weather conditions. As we find clear differences between night-time and daytime flux measurements as well as between stratified and lake mixing periods, it is advisable to prefer frequent and diverse sampling over daytimeonly measurements, which can lead to biases in greenhouse gas budget estimates.
Data availability. Eddy covariance, water column temperature and $\mathrm{CO}_{2}$ concentration and meteorological data are available in the AVAA - Open research data publishing platform (http:// openscience.fi/avaa). The metadata of the observations are available via the ETSIN service. Data from manual measurements are available upon request from the first author. 


\section{Appendix A}
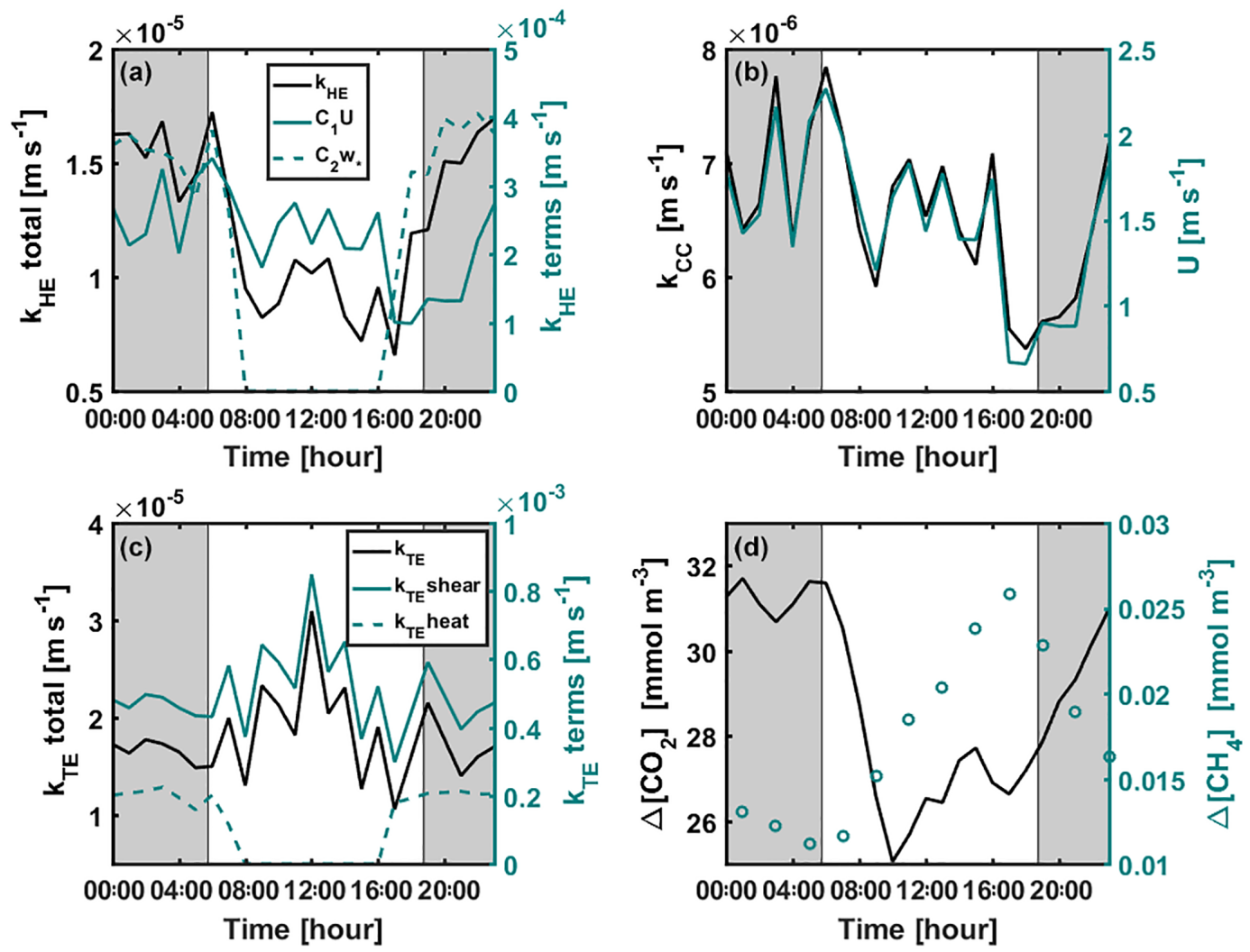

Figure A1. Diurnal variation of (a) $k_{\mathrm{HE}}$ and its shear and convective terms (Eq. 9), (b) $k_{\mathrm{CC}}$ and wind speed, (c) $k_{\mathrm{TE}}$ and its shear $\left(k_{\mathrm{TE}} s h e a r=\right.$ $\frac{c_{1} u_{* \mathrm{~W}}^{3}}{\kappa z}$ or $k_{\mathrm{TE}}$ shear $\left.=\frac{c_{3} u_{* \mathrm{~W}}^{3}}{\kappa z}\right)$ and convective $\left(k_{\mathrm{TE}}\right.$ heat $=c_{2}|\beta|$ or $k_{\mathrm{TE}}$ heat $\left.=0\right)$ terms $($ Eq. 8$)$, and $(\mathbf{d}) \mathrm{CO}_{2}$ and $\mathrm{CH}_{4}$ concentration differences between air and surface water during the stratified period 11-21 September 2014. Shear and convective terms in subplots (a) and (c) are not corrected with the Schmidt number. Grey areas represent night-time. 

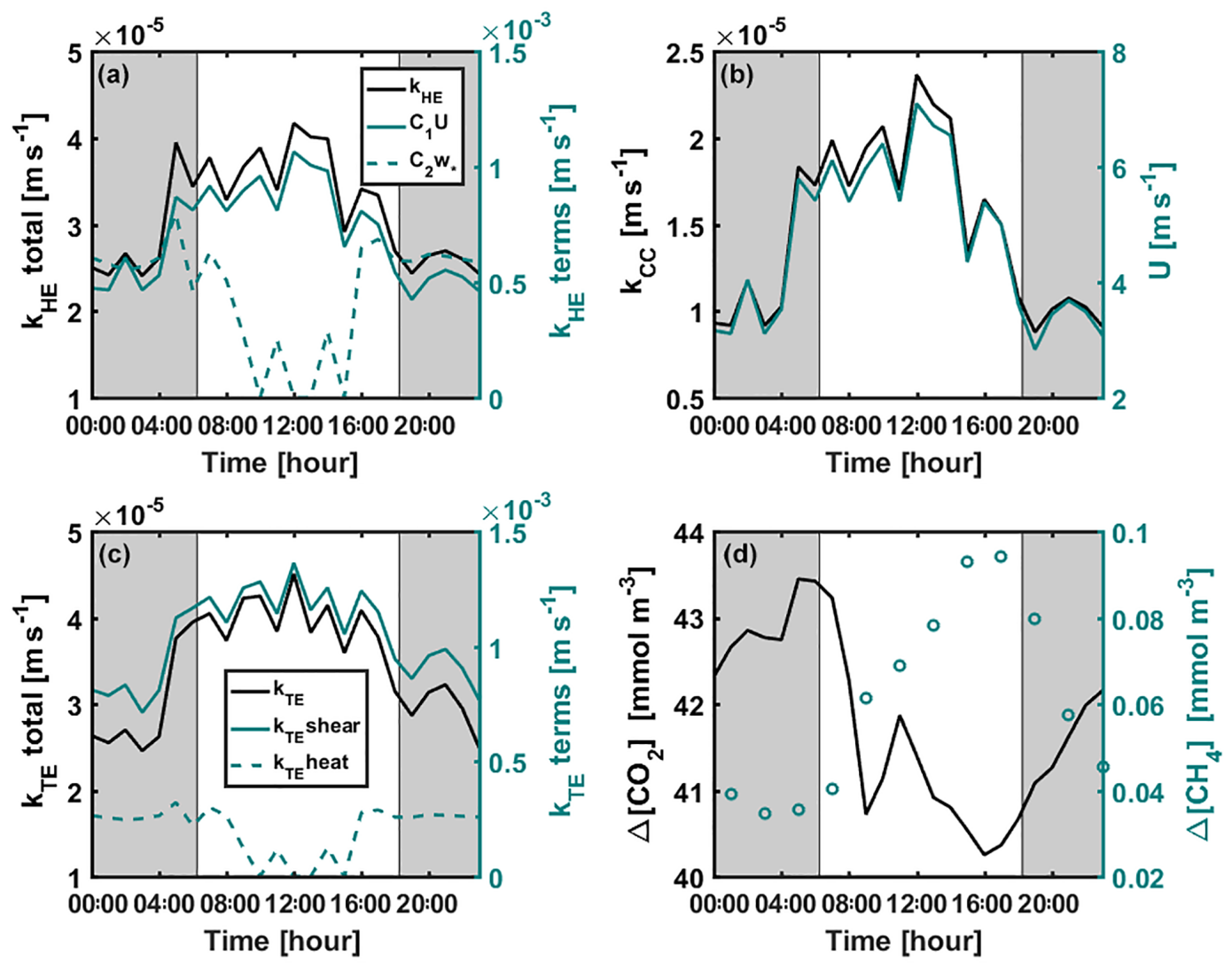

Figure A2. Diurnal variation of (a) $k_{\mathrm{HE}}$ and its shear and convective terms (Eq. 9), (b) $k_{\mathrm{CC}}$ and wind speed, (c) $k_{\mathrm{TE}}$ and its shear $\left(k_{\mathrm{TE}} \mathrm{shear}=\right.$ $\frac{c_{1} u_{* \mathrm{~W}}^{3}}{\kappa z}$ or $k_{\mathrm{TE}}$ shear $\left.=\frac{c_{3} u_{* \mathrm{~W}}^{3}}{\kappa z}\right)$ and convective $\left(k_{\mathrm{TE}}\right.$ heat $=c_{2}|\beta|$ or $k_{\mathrm{TE}}$ heat $\left.=0\right)$ terms $($ Eq. 8$)$, and $(\mathbf{d}) \mathrm{CO}_{2}$ and $\mathrm{CH}_{4}$ concentration differences between air and surface water during the mixing period 22-26 September 2014. Shear and convective terms in subplots (a) and (c) are not corrected with the Schmidt number. Grey areas represent night-time. 
Author contributions. IM, DB, JH, MR and TV designed the field experiments. KME, MR, AO and JH carried out manual field measurements. KME, IM and OP participated in eddy covariance data processing and analysis. TB and AL carried out automatic gas concentration measurements in the water column. All authors participated in analysing the results, and KME and IM prepared the manuscript with contributions from all co-authors.

Competing interests. The authors declare that they have no conflict of interest.

Acknowledgements. We thank the Hyytiälä Forestry Field Station staff for all their technical support and Maria Gutierrez de los Rios for her help during the measurement campaign. This study was supported by EU project GHG-LAKE (612642), Academy of Finland (CarLAC (281196) project, Centre of Excellence (272041), Academy Professor projects (284701 and 282842)), SRC-VR and ERC 725546 and ICOS-FINLAND (281255).

Edited by: Gwenaël Abril

Reviewed by: two anonymous referees

\section{References}

Aubinet, M., Vesala, T., and Papale, D. (Eds.): Eddy covariance: a practical guide to measurement and data analysis, Springer Science \& Business Media, 2012.

Bastviken, D., Cole, J., Pace, M., and Tranvik, L.: Methane emissions from lakes: Dependence of lake characteristics, two regional assessments, and a global estimate, Global Biogeoch. Cy., 18, GB4009, https://doi.org/10.1029/2004GB002238, 2004.

Bastviken, D., Santoro, A. L., Marotta, H., Pinho, L. Q., Calheiros, D. F., Crill, P., and Enrich-Prast, A.: Methane emissions from Pantanal, South America, during the low water season: toward more comprehensive sampling, Environ. Sci. Technol., 44, 54505455, 2010.

Bastviken, D., Tranvik, L. J., Downing, J. A., Crill, P. M., and Enrich-Prast, A.: Freshwater methane emissions offset the continental carbon sink, Science, 331, 50-50, 2011.

Blees, J., Niemann, H., Erne, M., Zopfi, J., Schubert, C. J., and Lehmann, M. F.: Spatial variations in surface water methane super-saturation and emission in Lake Lugano, southern Switzerland, Aquat. Sci., 77, 535-545, https://doi.org/10.1007/s00027015-0401-z, 2015.

Bussmann, I.: Methane release through resuspension of littoral sediment, Biogeochemistry, 74, 283-302, https://doi.org/10.1007/s10533-004-2223-2, 2005.

Cole, J. J. and Caraco, N. F.: Atmospheric exchange of carbon dioxide in a low-wind oligotrophic lake measured by the addition of $\mathrm{SF}_{6}$, Limnol. Oceanogr., 43, 647-656, 1998.

Cole, J. J., Caraco, N. F., Kling, G. W., and Kratz, T. K.: Carbon dioxide supersaturation in the surface waters of lakes, Science (New York, N.Y.), 265, 1568-1570, 1994.

Cole, J. J., Prairie, Y. T., Caraco, N. F., McDowell, W. H., Tranvik, L. J., Striegl, R. G., Duarte, C. M., Kortelainen, P., Downing, J. A., and Middelburg, J. J.: Plumbing the global carbon cy- cle: integrating inland waters into the terrestrial carbon budget, Ecosystems, 10, 172-185, 2007.

Duc, N. T., Silverstein, S., Lundmark, L., Reyier, H., Crill, P., and Bastviken, D.: Automated flux chamber for investigating gas flux at water-air interfaces, Environ. Sci. Technol., 47, 968-975, 2013.

Dumestre, J. F., Guézennec, J., Galy-Lacaux, C., Delmas, R., Richard, S., and Labroue, L.: Influence of light intensity on methanotrophic bacterial activity in Petit Saut Reservoir, French Guiana, Appl. Environ. Microbiol., 65, 534-539, 1999.

Eugster, W., Kling, G., Jonas, T., McFadden, J. P., Wüest, A., MacIntyre, S., and Chapin, F. S.: $\mathrm{CO}_{2}$ exchange between air and water in an Arctic Alaskan and midlatitude Swiss lake: Importance of convective mixing, J. Geophys. Res.-Atmos. (1984-2012), 108, 4362, https://doi.org/10.1029/2002JD002653, 2003.

Eugster, W., DelSontro, T., and Sobek, S.: Eddy covariance flux measurements confirm extreme $\mathrm{CH}_{4}$ emissions from a Swiss hydropower reservoir and resolve their short-term variability, Biogeosciences, 8, 2815-2831, https://doi.org/10.5194/bg-8-28152011, 2011.

Finkelstein, P. L. and Sims, P. F.: Sampling error in eddy correlation flux measurements, J. Geophys. Res.-Atmos., 106, 3503-3509, 2001.

Gålfalk, M., Bastviken, D., Fredriksson, S., and Arneborg, L.: Determination of the piston velocity for water-air interfaces using flux chambers, acoustic Doppler velocimetry, and IR imaging of the water surface, J. Geophys. Res.-Biogeosci., 118, 770-782, https://doi.org/10.1002/jgrg.20064, 2013.

Hari, P. and Kulmala, M.: Station for Measuring EcosystemAtmosphere Relations (SMEAR II), Boreal Environ. Res., 10, 315-322, 2005.

Hari, P., Pumpanen, J., Huotari, J., Kolari, P., Grace, J., Vesala, T., and Ojala, A.: High-frequency measurements of productivity of planktonic algae using rugged nondispersive infrared carbon dioxide probes, Limnol. Oceanogr., 6, 347-354, 2008.

Heiskanen, J. J., Mammarella, I., Haapanala, S., Pumpanen, J., Vesala, T., MacIntyre, S., and Ojala, A.: Effects of cooling and internal wave motions on gas transfer coefficients in a boreal lake, Tellus B, 66, 22827, https://doi.org/10.3402/tellusb.v66.22827, 2014.

Heiskanen, J. J., Mammarella, I., Ojala, A., Stepanenko, V., Erkkilä, K.-M., Miettinen, H., Sandström, H., Eugster, W., Leppäranta, M., Järvinen, H., Vesala, T., and Nordbo, A.: Effects of water clarity on lake stratification and lake-atmosphere heat exchange, J. Geophys. Res.-Atmos., 120, 7412-7428, https://doi.org/10.1002/2014JD022938, 2015.

Huotari, J., Ojala, A., Peltomaa, E., Nordbo, A., Launiainen, S., Pumpanen, J., Rasilo, T., Hari, P., and Vesala, T.: Long term direct $\mathrm{CO}_{2}$ flux measurements over a boreal lake: Five years of eddy covariance data, Geophys. Res. Lett., 38, L18401, https://doi.org/10.1029/2011GL048753, 2011.

Imberger, J.: The diurnal mixed layer, Limnol. Oceanogr., 30, 737$770,1985$.

Keller, M. and Stallard, R. F.: Methane emission by bubbling from Gatun Lake, Panama, J. Geophys. Res.-Atmos., 99, 8307-8319, https://doi.org/10.1029/92JD02170, 1994.

Lehner, B. and Döll, P.: Development and validation of a global database of lakes, reservoirs and wetlands, J. Hydrol., 296, 1-22, https://doi.org/10.1016/j.jhydrol.2004.03.028, 2004. 
Liu, H., Peters, G., and Foken, T.: New equations for sonic temperature variance and buoyancy heat flux with an omnidirectional sonic anemometer, Bound.-Lay. Meteorol., 100, 459-468, https://doi.org/10.1175/JHM-D-12-020.1, 2001.

Livingston, G. P. and Hutchinson, G. L.: Enclosure-based measurement of trace gas exchange: applications and sources of error, in: Biogenic trace gases: measuring emissions from soil and water, edited by: Matson, P. and Harriss, R., 14-51, Blackwell Science Ltd, 1995.

Lorke, A., Bodmer, P., Noss, C., Alshboul, Z., Koschorreck, M., Somlai-Haase, C., Bastviken, D., Flury, S., McGinnis, D. F., Maeck, A., Müller, D., and Premke, K.: Technical note: drifting versus anchored flux chambers for measuring greenhouse gas emissions from running waters, Biogeosciences, 12, 7013-7024, https://doi.org/10.5194/bg-12-7013-2015, 2015.

MacIntyre, S., Wanninkhof, R., and Chanton, J. P.: Trace gas exchange across the air-water interface in freshwater and coastal marine environments, in: Biogenic trace gases: measuring emissions from soil and water, edited by: Matson, P. and Harriss, R., 52-97, Blackwell Science Ltd, 1995.

Mammarella, I., Launiainen, S., Grönholm, T., Keronen, P., Pumpanen, J., Rannik, Ü., and Vesala, T.: Relative humidity effect on the high-frequency attenuation of water vapor flux measured by a closed-path eddy covariance system, J. Atmos. Ocean. Tech., 26, 1856-1866, https://doi.org/10.1175/2009JTECHA1179.1, 2009.

Mammarella, I., Nordbo, A., Rannik, Ü., Haapanala, S., Levula, J., Laakso, H., Ojala, A., Peltola, O., Heiskanen, J., Pumpanen, J., and Vesala, T.: Carbon dioxide and energy fluxes over a small boreal lake in Southern Finland, J. Geophys. Res.-Biogeosci., 120, 1296-1314, https://doi.org/10.1002/2014JG002873, 2015.

Mammarella, I., Peltola, O., Nordbo, A., Järvi, L., and Rannik, Ü.: Quantifying the uncertainty of eddy covariance fluxes due to the use of different software packages and combinations of processing steps in two contrasting ecosystems, Atmos. Meas. Tech., 9, 4915-4933, https://doi.org/10.5194/amt-9-4915-2016, 2016.

Miettinen, H., Pumpanen, J., Heiskanen, J. J., H., A., Mammarella, I., Ojala, A., Levula, J., and Rantakari, M.: Towards a more comprehensive understanding of lacustrine greenhouse gas dynamics - two-year measurements of concentrations and fluxes of $\mathrm{CO}_{2}$, $\mathrm{CH}_{4}$ and $\mathrm{N}_{2} \mathrm{O}$ in a typical boreal lake surrounded by managed forests, Boreal Environ. Res., 20, 75-89, 2015.

Mitchell, B. G., Broody, E. A., Holm-Hansen, O., and McClain, C.: Inhibitory effect of light on methane oxidation in the pelagic water column of a mesotrophic lake (Lake Biwa, Japan), Limnol. Oceanogr, 36, 1662-1677, 2005.

Natchimuthu, S., Sundgren, I., Gålfalk, M., Klemedtsson, L., Crill, P., Danielsson, A., and Bastviken, D.: Spatio-temporal variability of lake $\mathrm{CH}_{4}$ fluxes and its influence on annual whole lake emission estimates, Limnol. Oceanogr., 61, S13-S26, https://doi.org/10.1002/lno.10222, 2016.

Ojala, A., Lopez Bellido, J., Tulonen, T., Kankaala, P., and Huotari, J.: Carbon gas fluxes from a brown-water and a clear-water lake in the boreal zone during a summer with extreme rain events, Limnol. Oceanogr., 56, 61-76, https://doi.org/10.4319/1o.2011.56.1.0061, 2011.

Podgrajsek, E., Sahlée, E., Bastviken, D., Holst, J., Lindroth, A., Tranvik, L., and Rutgersson, A.: Comparison of floating chamber and eddy covariance measurements of lake greenhouse gas fluxes, Biogeosciences, 11, 4225-4233, https://doi.org/10.5194/bg-11-4225-2014, 2014a.

Podgrajsek, E., Sahlée, E., and Rutgersson, A.: Diurnal cycle of lake methane flux, J. Geophys. Res.-Biogeosci., 119, 236-248, https://doi.org/10.1002/2013JG002327, 2014b.

Podgrajsek, E., Sahlée, E., and Rutgersson, A.: Diel cycle of lakeair $\mathrm{CO}_{2}$ flux from a shallow lake and the impact of waterside convection on the transfer velocity, J. Geophys. Res.-Biogeosci., 120, 29-38, https://doi.org/10.1002/2014JG002781, 2015.

Rannik, Ü., Peltola, O., and Mammarella, I.: Random uncertainties of flux measurements by the eddy covariance technique, Atmos. Meas. Tech., 9, 5163-5181, https://doi.org/10.5194/amt-9-51632016, 2016.

Rantakari, M. and Kortelainen, P.: Interannual variation and climatic regulation of the $\mathrm{CO}_{2}$ emission from large boreal lakes, Glob. Change Biol., 11, 1368-1380, 2005.

Raymond, P. A., Hartmann, J., Lauerwald, R., Sobek, S., McDonald, C., Hoover, M., Butman, D., Striegl, R., Mayorga, E., and Humborg, C.: Global carbon dioxide emissions from inland waters, Nature, 503, 355-359, https://doi.org/10.1038/nature12760, 2013.

Schubert, C. J., Diem, T., and Eugster, W.: Methane emissions from a small wind shielded lake determined by eddy covariance, flux chambers, anchored funnels, and boundary model calculations: a comparison, Environ. Sci. Technol., 46, 4515-4522, 2012.

Seinfeld, J. H. and Pandis, S. N.: Atmospheric chemistry and physics: from air pollution to climate change, John Wiley \& Sons, 2016.

Stepanenko, V., Mammarella, I., Ojala, A., Miettinen, H., Lykosov, V., and Vesala, T.: LAKE 2.0: a model for temperature, methane, carbon dioxide and oxygen dynamics in lakes, Geosci. Model Dev., 9, 1977-2006, https://doi.org/10.5194/gmd-9-1977-2016, 2016.

Tedford, E. W., MacIntyre, S., Miller, S. D., and Czikowsky, M. J.: Similarity scaling of turbulence in a temperate lake during fall cooling, J. Geophys. Res.-Oceans, 119, 4689-4713, https://doi.org/10.1002/2014JC010135, 2014.

Tranvik, L. J., Downing, J. A., Cotner, J. B., Loiselle, S. A., Striegl, R. G., Ballatore, T. J., Dillon, P., Finlay, K., Fortino, K., and Knoll, L. B.: Lakes and reservoirs as regulators of carbon cycling and climate, Limnol. Oceanogr., 54, 2298-2314, https://doi.org/10.4319/lo.2009.54.6_part_2.2298, 2009.

Verpoorter, C., Kutser, T., Seekell, D. A., and Tranvik, L. J.: A global inventory of lakes based on high-resolution satellite imagery, Geophys. Res. Lett., 41, 6396-6402, https://doi.org/10.1002/2014GL060641, 2014.

Vesala, T., Huotari, J., Rannik, U., Suni, T., Smolander, S., Sogachev, A., Launiainen, S., and Ojala, A.: Eddy covariance measurements of carbon exchange and latent and sensible heat fluxes over a boreal lake for a full open water period, J. Geophys. Res.Atmos., 111, https://doi.org/10.1029/2005JD006365, 2006.

Vickers, D. and Mahrt, L.: Quality control and flux sampling problems for tower and aircraft data, J. Atmos. Ocean. Tech., 14, 512 526, 1997.

Warneck, P. and Williams, J.: The atmospheric Chemist's companion: numerical data for use in the atmospheric sciences, Springer Science \& Business Media, 2012. 